\title{
Geographic Origin Determination OF RubY
}

Aaron C. Palke, Sudarat Saeseaw, Nathan D. Renfro, Ziyin Sun, and Shane F. McClure

Over the last several decades, geographic origin determination for fine rubies has become increasingly important in the gem trade. In the gemological laboratory, rubies are generally broken down into two groups based on their trace element chemistry: marble-hosted (low-iron) rubies and high-iron rubies. High-iron rubies are usually a straightforward identification based on their inclusions and trace element profiles. Marble-hosted rubies can be more challenging, with some deposits showing overlap in some of their inclusion scenes. But many marblehosted rubies, especially Burmese stones from Mogok and Mong Hsu, can be accurately identified based on their internal features and trace element profiles. This contribution will outline the methods and criteria used at GIA for geographic origin determination for ruby.

T he world ruby market has changed dramatically in modern times, especially in the last decade with the discovery and development of ruby mining in Mozambique (Chapin et al., 2015). As the gem trade has witnessed turbulent and dramatic changes in the ruby supply chain, the concept of geographic origin has become increasingly important to people buying and selling fine rubies. Often, the origin of a ruby plays an important role in the value placed on the stone, especially for exceptional quality rubies from Myanmar (figure 1). As with other colored gemstones, the ruby trade relies to a large extent on reputable gemological laboratories to make these origin determinations. In the second material-specific article of this series we delve into the world of rubies, their gemological properties, and characteristics that may aid in geographic origin determination. The following sections will detail the origin data GIA has collected for rubies and describe the methodology used in the lab to apply this data to geographic origin work.

\section{SAMPLES AND ANALYTICAL METHODS}

Rubies included in this study are predominantly from GIA's reference collection, which was assembled over more than 10 years by GIA's field gemology department. Stones in GIA's reference collection

See end of article for About the Authors and Acknowledgments.

Gems \& Gemologr, Vol. 55, No. 4, pp. 580-612,

http://dx.doi.org/10.5741/GEMS.55.4.580

(C) 2019 Gemological Institute of America were obtained by skilled gemologists from reliable sources and were collected as close to the mining source as possible (see Vertriest et al., 2019, pp. 490511 of this issue). When necessary, the data from the reference collection were supplemented by stones from the personal collections of the authors of this

\section{In Brief}

- Geographic origin can have a significant impact on the value of fine rubies.

- Origin for marble-hosted rubies can often be determined from inclusions and trace element chemistry, but there are areas of overlap.

- Inclusions and trace element chemistry typically make origin determination for high-iron rubies much more straightforward.

study or from GIA's museum collection. The trace element data were collected from 280 marble-hosted ruby samples and 219 high-iron samples: 65 samples from Myanmar, 93 from Vietnam, 74 from Afghanistan, 48 from Tajikistan, 34 from Cambodia, 7 from Thailand, 93 from Madagascar, and 85 from Mozambique.

Trace element chemistry was collected over the course of several years at GIA using two different laser ablation-inductively coupled plasma-mass spectrometry (LA-ICP-MS) systems. The ICP-MS used was either a Thermo Fisher X-Series II or iCAP 


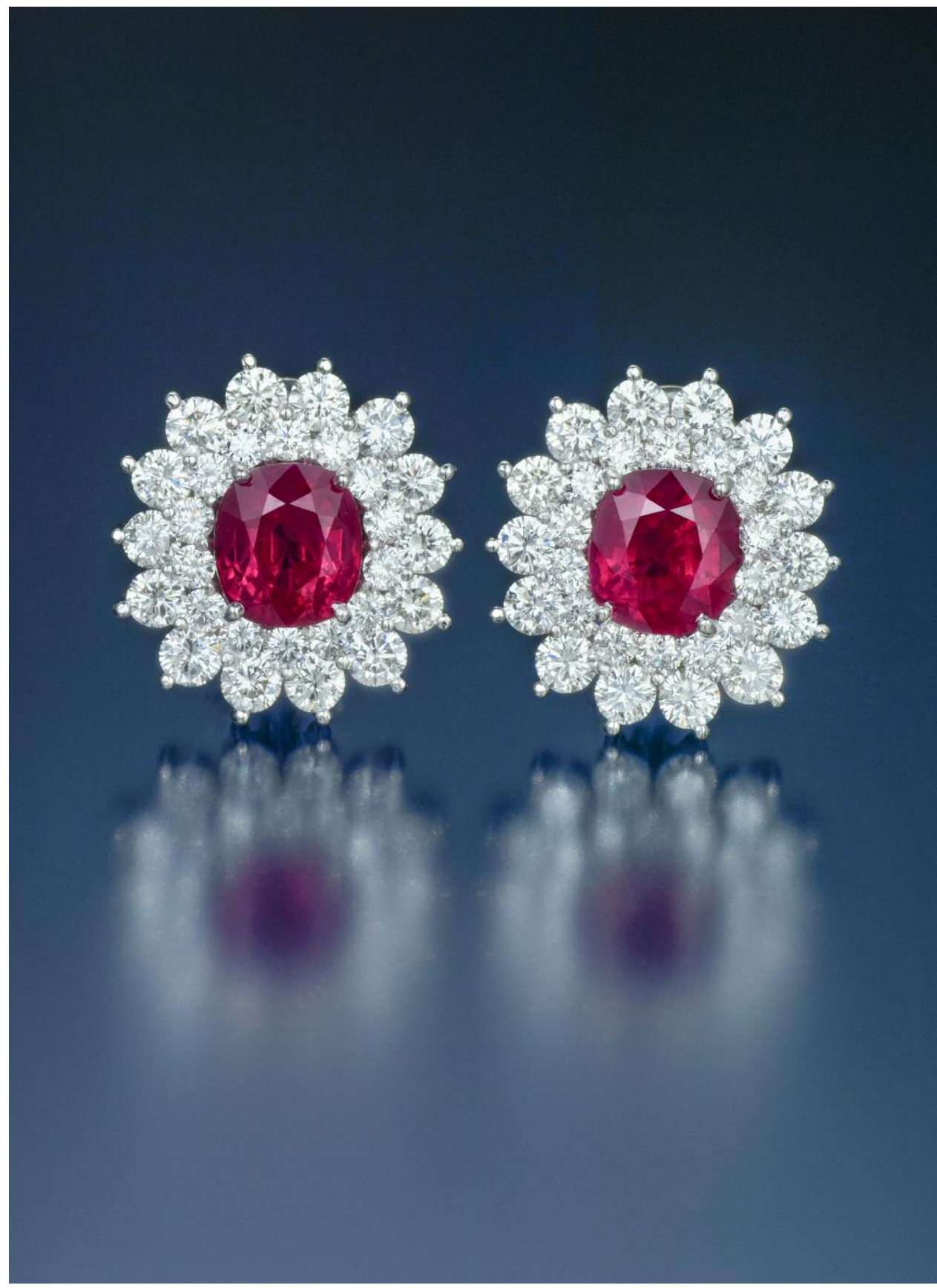

Figure 1. Pair of ruby and diamond earrings from Mong Hsu, Myanmar, 6.04 carats total. Photo by Robert Weldon/GIA; courtesy of Robert E. Kane, Fine Gems International.

Qc system, coupled to an Elemental Scientific Lasers NWR 213 laser ablation system with a frequencyquintupled Nd:YAG laser (213 nm wavelength with 4 ns pulse width). Ablation was carried out with 55 $\mu \mathrm{m}$ spot sizes, with fluence of $8-10 \mathrm{~J} / \mathrm{cm}^{2}$ and repetition rates of either 15 or $20 \mathrm{~Hz} .{ }^{27} \mathrm{Al}$ was used as an internal standard at 529250 ppmw with custom-developed synthetic corundum used as external standards (Wang et al., 2006; Stone-Sundberg et al., 2017). Detection limits varied slightly through the course of the analyses but were generally $0.1-0.3$ ppma $\mathrm{Mg}$, 0.5-2.0 ppma Ti, 0.03-0.2 ppma V, 5-20 ppma Fe, and 0.03-0.07 ppma Ga. Cr is not used in the laboratory as a discriminant element, after years of testing showed it is not useful for origin. Additionally, ruby/pink sapphire calls are made based on color and not $\mathrm{Cr}$ concentrations. Trace element values are reported here in parts per million on an atomic basis rather than the more typical parts per million by weight unit used for trace elements in many geo- 
chemical studies. Units of ppma are the standard used in GIA laboratories for corundum, as this allows a more facile analysis of crystal chemical properties and an understanding of the color mechanisms of sapphire and ruby. Conversion factors are determined by a simple formula that can be found in table 1 of Emmett et al. (2003). The reference samples are diverse in terms of their appearance and presence/absence of silk, clouds, and otherwise included areas. Every effort was made to sample as many chemically distinct areas in heterogeneous samples as possible to ensure robust representation of silky, cloudy, and unincluded ruby trace element chemistry.

Inclusions were identified, when possible, using Raman spectroscopy with a Renishaw inVia Raman microscope system. The Raman spectra of the inclusions were excited by a Modu-Laser Stellar-REN Arion laser producing highly polarized light at $514 \mathrm{~nm}$ and collected at a nominal resolution of $3 \mathrm{~cm}^{-1}$ in the 2000-200 $\mathrm{cm}^{-1}$ range. In many cases, the confocal capabilities of the Raman system allowed inclusions beneath the surface to be analyzed.

UV-Vis spectra were recorded with a Hitachi U2910 spectrometer or a PerkinElmer Lambda 950 in the range of $190-1100 \mathrm{~nm}$ with a $1 \mathrm{~nm}$ spectral resolution and a scan speed of $400 \mathrm{~nm} / \mathrm{min}$. UV-Vis-NIR spectra are presented as absorption coefficient $(\alpha)$ in units of $\mathrm{cm}^{-1}$ where $\alpha=\mathrm{A} \times 2.303 / \mathrm{t}$, with $\mathrm{A}=\mathrm{ab}$ sorbance and $\mathrm{t}=$ path length in $\mathrm{cm}$.

\section{MARBLE-HOSTED AND HIGH-IRON RUBIES}

As with blue sapphires, the first step in making a geographic origin determination for rubies is to make a broad division into two groups-in this case, marble-hosted rubies and so-called high-iron rubies. The first group encompasses rubies from the legendary mines in Mogok in what is now Myanmar, as well as more modern deposits in Vietnam, Tajikistan, Afghanistan, and Mong Hsu in Myanmar. These marble-hosted ruby deposits are mostly located in Southeast and Central Asia and were formed during the Himalayan orogeny. During this geological event, platform carbonates (limestones) that formed in the warm shallow sea between the Indian and Asian plates were buried and subjected to extreme temperatures and pressures when these two plates collided. Fluids and molten salts that circulated through the marbles formed in this process were responsible for mobilizing aluminum and chromium in these rocks and forming ruby (Garnier et al., 2008; Giuliani and Groat, 2019, pp. 464-489 of this issue).
On the other hand, "high-iron ruby" is a catchall term used to describe the second group of rubies, which can be distinguished by their distinctive trace element chemistry. Rubies in this group have much more diverse geological origins, ranging from basaltrelated rubies such as those found in Thailand and Cambodia to more metamorphic or metasomatic rubies found in Mozambique and Madagascar. The common thread, geologically speaking, seems to be that rubies in this group probably were derived from similar geological formations, which was most likely (ultra)mafic or basic intrusive igneous rocks (Mercier et al., 1999; Smith et al., 2016; Fanka and Sutthirat, 2018; Sutthirat et al., 2018; Palke et al., 2018). It was these iron-rich rocks that imparted their characteristic trace element profiles on the rubies (see Giuliani and Groat, 2019, pp. 464-489 of this issue, for more detailed discussion of the geology of these deposits).

Unfortunately, there is no spectroscopic test available to easily distinguish between these two groups of rubies as there is for metamorphic and magmatic blue sapphires. In many cases, a glance through the microscope can easily make this separation, as typical inclusion scenes tend to be different between the two groups. Intensity of fluorescence can also be an indicator: The iron in the "high-iron" group tends to inhibit fluorescence, and typically these rubies do not fluoresce as strongly as the marble-hosted rubies. In order to improve the accuracy of a geographic origin conclusion, however, trace element chemistry is important to consider as well. The marble-hosted rubies generally have iron concentrations below 200 ppma, with very few stones above 400 ppma, while iron contents in the high-iron rubies are mostly above 400 ppma. Assessing all the available data allows easy separation of rubies from these two groups in most cases, simplifying geographic origin determination by significantly reducing the number of potential locations. Those stones falling in between these two groups, with an iron content between 200 and 400 ppma, need to be considered very carefully, as several origins are possible in these cases.

\section{GEOGRAPHIC ORIGIN DETERMINATION: MARBLE-HOSTED RUBY INCLUSIONS}

In many cases, the geographic origin of marblehosted rubies is difficult to identify in the laboratory. Historically, things would have been simpler. For hundreds if not thousands of years, the mining town of Mogok in Burma (now Myanmar) was practically the sole source of this group of rubies (Themelis, 


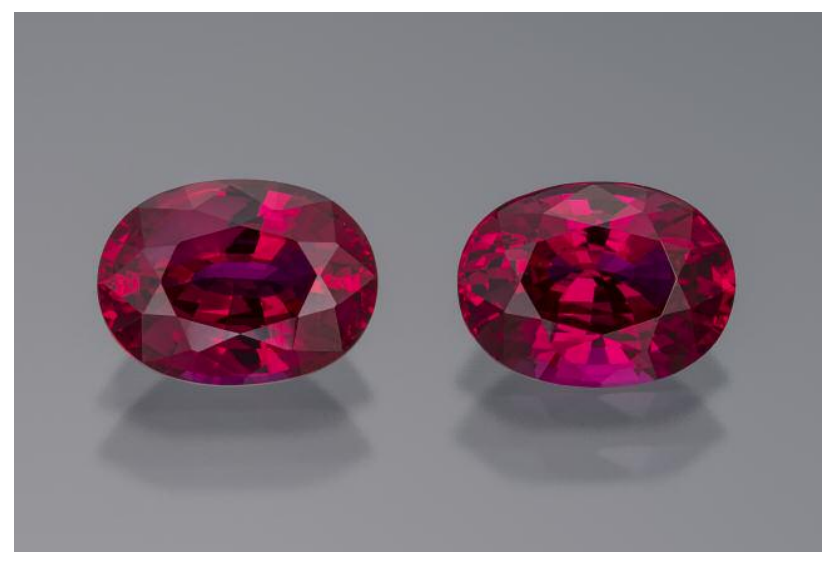

Figure 2. Matched pair of Burmese rubies from Mogok, approximately 4 carats total. Photo by Robert Weldon/GIA; courtesy of Amba Gem Corporation.

2008). The Afghan ruby mines at Jegdalek have had some production for several hundred years, but the output has never matched Mogok's in terms of quantity or quality (Garnier et al., 2008; Hughes et al., 2017). However, Mogok rubies started to see much more competition starting in the twentieth century with new finds of marble-hosted rubies in Vietnam, Tajikistan, and another deposit in Myanmar at Mong Hsu. Because all of these rubies were formed in the same geological event under similar geological conditions, their inclusion scenes and especially their trace element chemistry can sometimes be similar to those from the legendary deposit in Mogok.

For many stones coming through GIA's lab, inclusion scenes and trace element chemistry are enough to accurately determine a geographic origin. This is usually the case for Burmese rubies from Mogok and Mong Hsu, which often have typical inclusions. However, the reality of the situation is that in some cases a stone may not contain a diagnostic inclusion scene and the trace element chemistry may be ambiguous. In these situations, an "inconclusive" origin determination is the only appropriate answer. In the following sections we will lay out the exact criteria currently employed by GIA for making geographic origin determinations for marble-hosted rubies. Additional information about these rubies can be found in the following references: Kane et al. (1991), Brown (1992), Hughes (1994); Peretti et al. (1995), Smith (1998), Bowersox et al. (2000), Schwarz and Schmetzer (2001), Long et al. (2004a,b,c), Gübelin and Koivula (2008), Sorokina et al. (2015), and Hughes et al. (2017).

Typical Inclusion Scenes. Inclusion scenes often supply the bulk of the evidence in ascertaining geo-

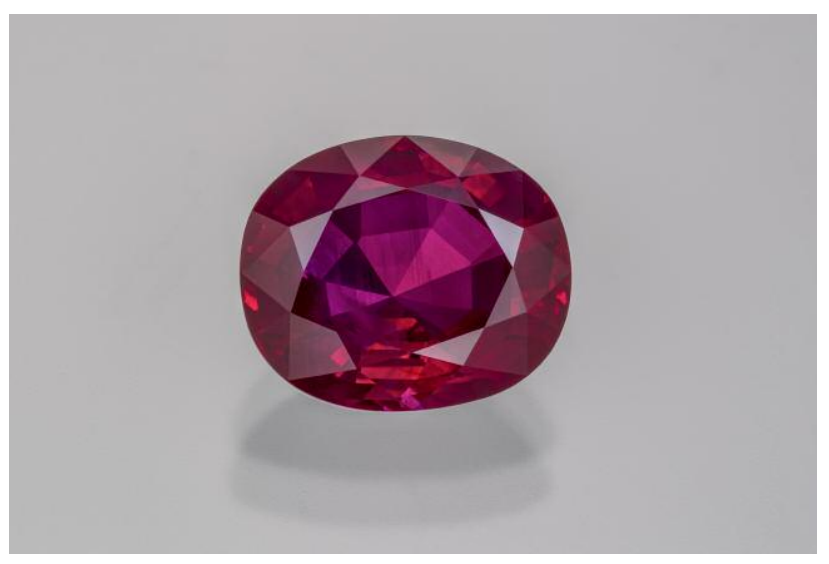

Figure 3. Burmese ruby from Mogok, approximately 4 ct. Photo by Robert Weldon/GIA; courtesy of Amba Gem Corporation.

graphic origin for marble-hosted rubies. Unfortunately, there are not any "diagnostic" mineral inclusions for rubies. All marble-hosted rubies can contain inclusions of calcite, apatite, and other common solid minerals. More often, the defining inclusion scenes are composed of characteristic patterns of silk, milky clouds, and patterned clouds. In the following sections we will offer examples of typical inclusion scenes for marble-hosted rubies from Myanmar, Vietnam, Afghanistan, and Tajikistan.

The Internal World of Burmese Rubies. Rubies come from two separate deposits in Myanmar: the historic Mogok region and the more recent Mong Hsu deposit. In general, Mogok has produced more important, finer-quality rubies (figures 2 and 3) while Mong Hsu has mostly supplied commercial-grade material. In the following sections, the inclusion scenes of Mogok and Mong Hsu rubies will be considered independently.

Several photomicrographs depicting typical inclusion scenes in Mogok rubies are shown in figures 49. The silk in Mogok rubies often occurs as nested concentrations of fine, long to short rutile needles (figure 4). These nests of silk often occur near the center of the stone, sometimes accompanied by inclusions of calcite and other minerals (figure 5). Silk in Mogok rubies often occurs as short reflective rutile needles with a flattened aspect, possibly exhibiting an arrowhead shape due to twinning of the rutile (figures 6-8). However, longer silk is also common in Mogok rubies (figures 4 and 5). Note that unlike many rubies from other deposits, Mogok rubies usually do not require heat treatment to optimize their color. This means that silk in these stones generally 


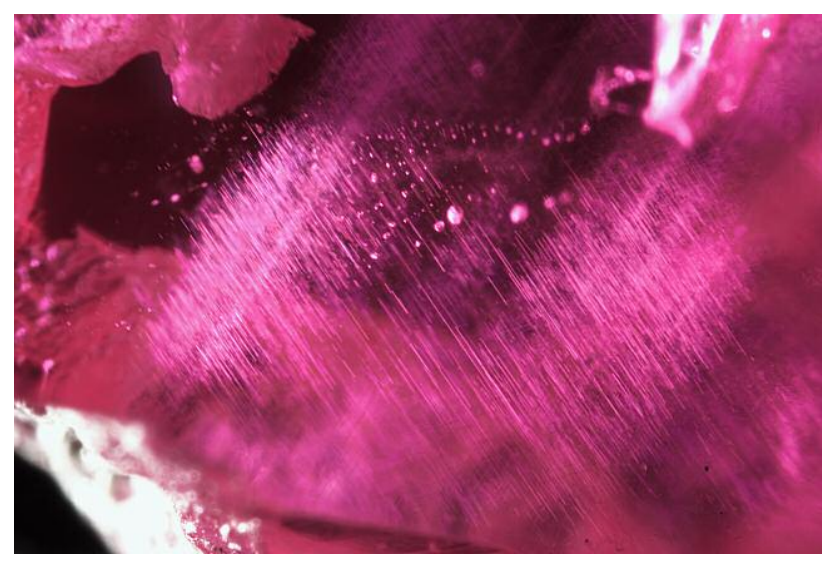

Figure 4. Dense concentrations of silk and rounded crystal inclusions suggest a Mogok, Myanmar, origin for this ruby. Photomicrograph by Charuwan Khowpong; field of view $2.37 \mathrm{~mm}$.

stays intact. While heat treatment of blue sapphires tends to destroy evidence of origin in the form of silk patterns, this is rarely the case for the silk seen in Mogok rubies. Another inclusion scene suggestive of a Mogok origin is distinctive roiled graining, which is likely caused by turbulent and rapid crystal growth when the rubies formed (figure 9). Distinct red and colorless zoning is often associated with this graining. Note that Burmese rubies from Mogok can often be identified by characteristic inclusion scenes such as iridescent short needles or nested silk, though there may be borderline cases where the inclusions

Figure 6. Shorter rutile silk with a flattened aspect, typical of Mogok rubies, creates vivid iridescence when viewed with intense fiber-optic illumination. Photomicrograph by Charuwan Khowpong; field of view $1.12 \mathrm{~mm}$.

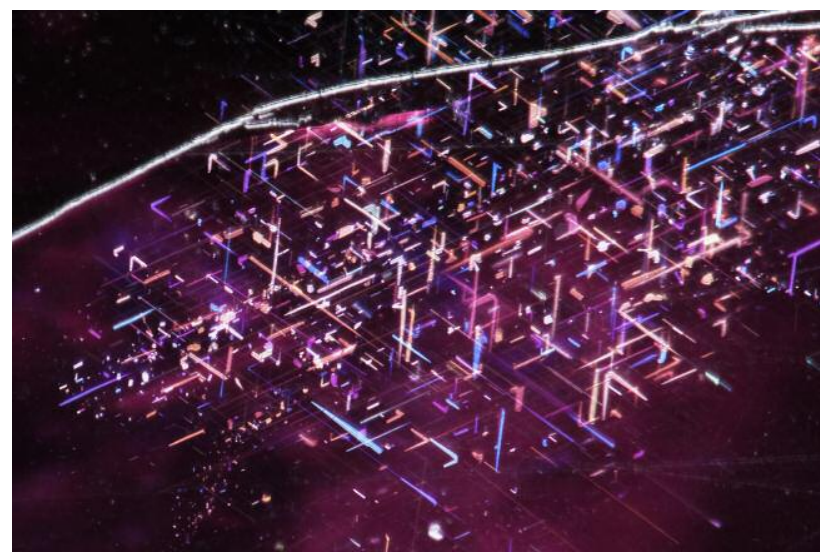

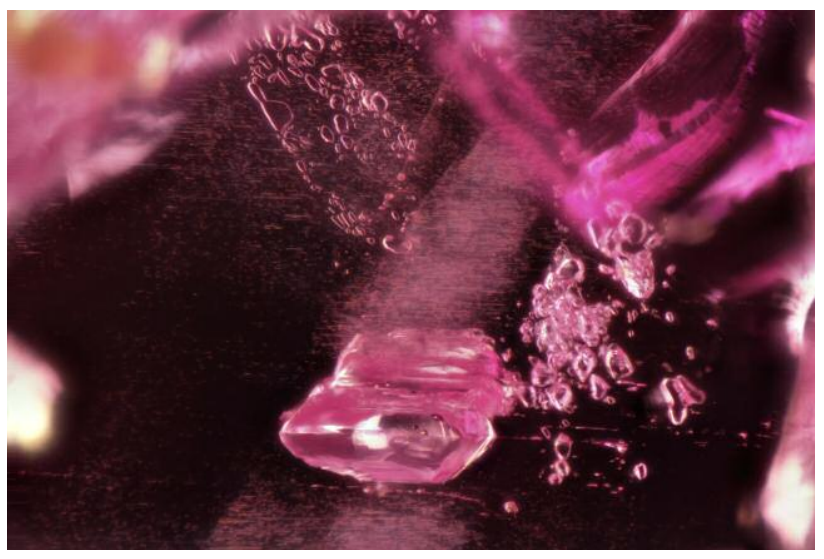

Figure 5. Dense concentrations of silk accompanied by rounded calcite crystals suggest a Burmese origin. Photomicrograph by Jonathan Muyal; field of view $1.99 \mathrm{~mm}$

are not conclusively Mogok but might still indicate such an origin (see the "Inclusion Scenes Gone Wrong" section below).

The ruby deposits in Mong Hsu were discovered only recently, in the later part of the twentieth century. Luckily, Mong Hsu rubies tend to have characteristic inclusion scenes that allow them to be easily separated from rubies from Mogok and other marblehosted rubies. Because dark blue zones and fractures are so common in Mong Hsu rubies in their natural state, most stones from this deposit are heat treated at high temperatures. Unheated Mong Hsu rubies are
Figure 7. Short, reflective platelet-like silk is characteristic of Mogok rubies. Photomicrograph by GIA; field of view $1.31 \mathrm{~mm}$.

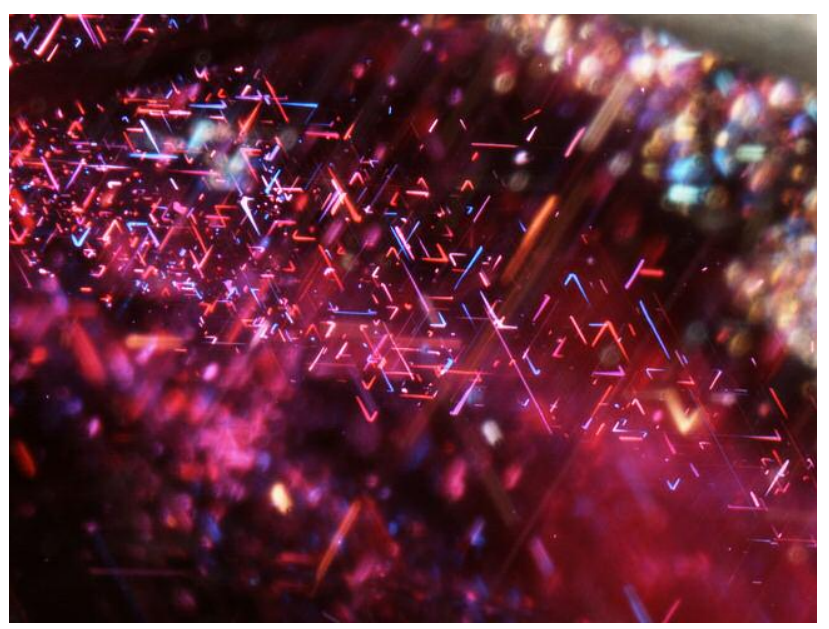




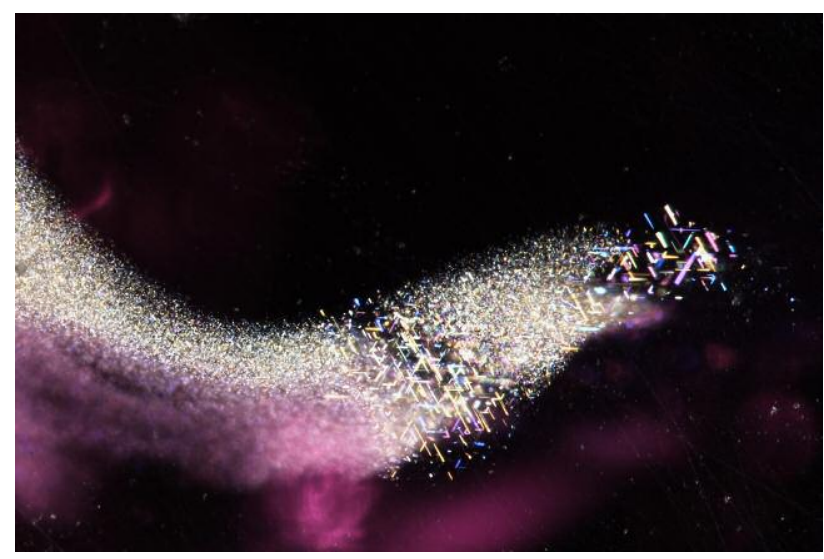

Figure 8. A mixture of flattened rutile needles is accompanied by a fine dusting of particulate silk in this Mogok ruby. Photomicrograph by Charuwan Khowpong; field of view $1.75 \mathrm{~mm}$.

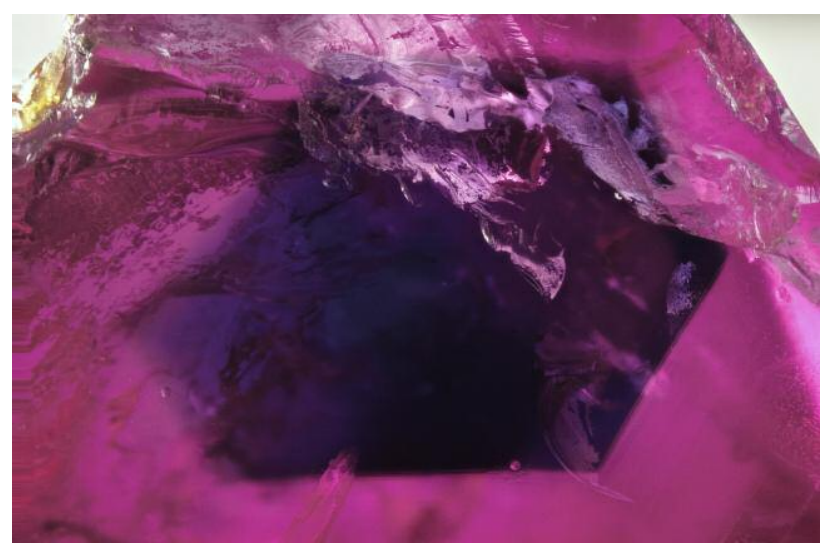

Figure 10. This deep blue hexagonal core is a telltale sign of an unheated Mong Hsu ruby's provenance. However, unheated Mong Hsu rubies are rarely encountered in the trade. Photomicrograph by Jonathan Muyal; field of view $4.79 \mathrm{~mm}$.

often distinguished by a dark blue core (figure 10). However, unheated material from Mong Hsu is rare. More commonly seen is a white, cloudy core produced by the heat treatment process (figure 11). Patterned clouds such as ladders and snowflake inclusions are typical of Mong Hsu rubies (figures 12 and 13). Stepped, angular graining is occasionally seen in Mong Hsu rubies as well (figure 14). More recently, flux-as-

Figure 12. Snowflake inclusions and other types of patterned clouds are typical inclusions in heated Mong Hsu rubies. Photomicrograph by Jonathan Muyal; field of view $4.10 \mathrm{~mm}$.

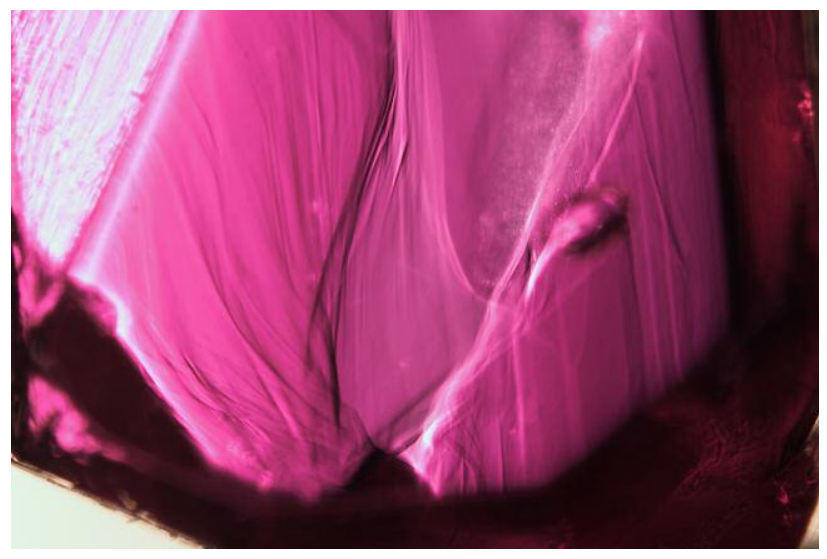

Figure 9. Roiled graining is consistent with a Mogok origin in this ruby. Photomicrograph by Charuwan Khowpong; field of view $2.83 \mathrm{~mm}$.

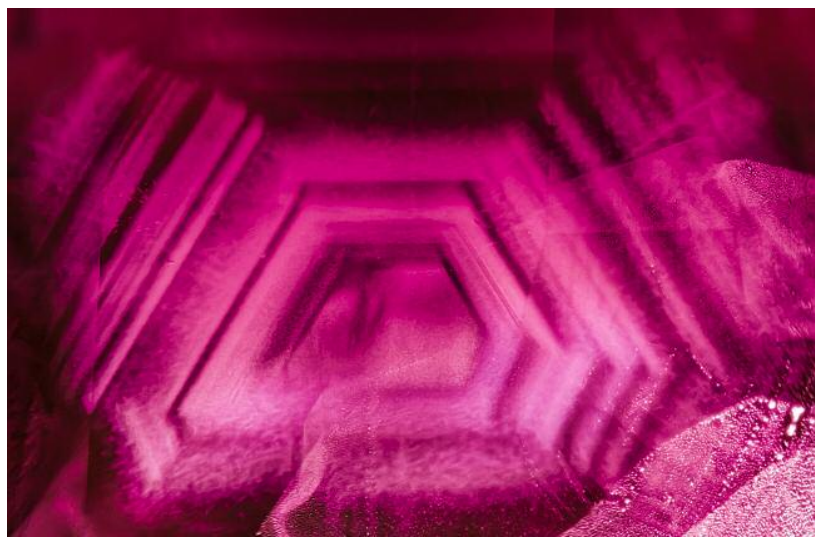

Figure 11. Heated Mong Hsu rubies are often identified by dense hexagonal white clouds in their cores. Photomicrograph by Nathan Renfro; field of view 2.97 $\mathrm{mm}$.

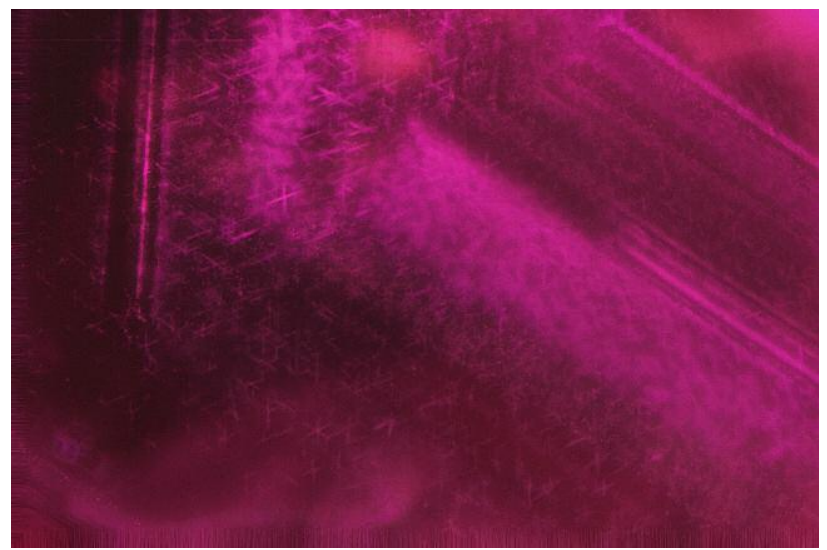




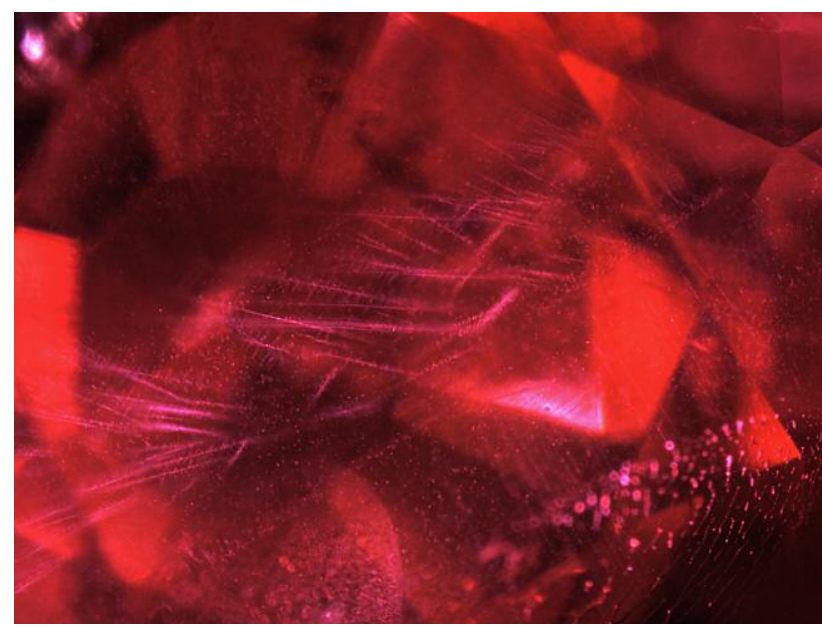

Figure 13. Ladder- and streamer-like inclusions provide an indication of this ruby's Mong Hsu origin. Photomicrograph by GIA; field of view $4.68 \mathrm{~mm}$.

sisted heating of rubies has been widely used with Mong Hsu rubies, and flux-healed fractures are prevalent in much of the material on the market. Solid mineral inclusions are rare in these rubies.

The Internal World of Vietnamese Rubies. The ruby deposits in Vietnam, discovered in the late twentieth century, have yielded fine rubies of exceptional quality (figures 15 and 16), rivaling those from the famed Mogok Valley (Kane et al., 1991; Brown, 1992; Khoi et al., 2011). As with most marble-hosted rubies, there tends to be significant overlap in their properties between various geographic localities, especially when it comes to trace element chemistry (see the

Figure 15. A 1.32 ct Vietnamese ruby. Photo by Orasa Weldon.

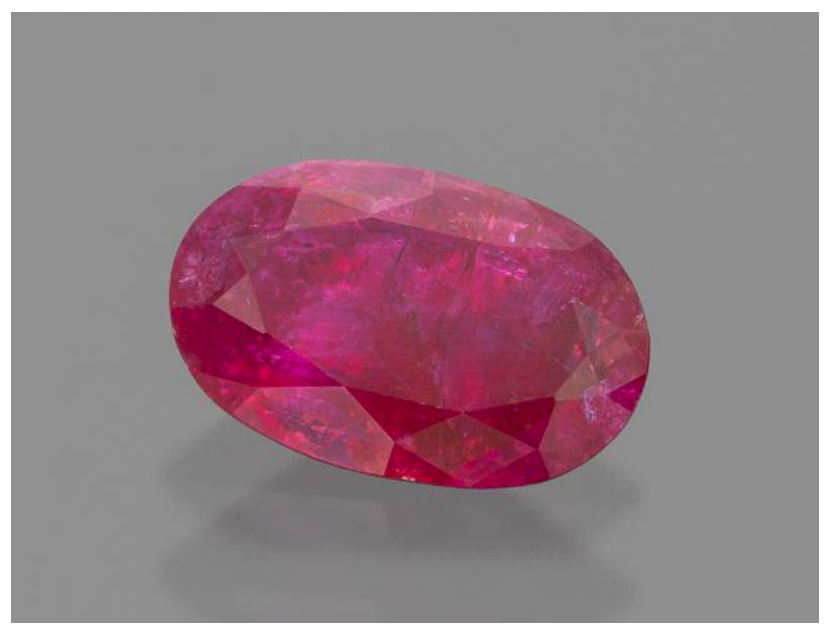

"Trace Element Chemistry" section below). However, Vietnamese rubies may have distinctive inclusion scenes that help in determining their provenance. Especially characteristic is the presence of dense, angular milky banding (figures 17 and 18). Coarse, patterned clouds such as snowflake and ladder inclusions are relatively common in Vietnamese rubies and tend to be larger than those found in Mong Hsu rubies (figure 18). Coarse, oriented silk is also seen in some Vietnamese rubies, sometimes resembling the silk in Mogok rubies, although their inclusion scenes can usually be distinguished by the experienced gemologist. Vietnamese rubies often have blue color zoning that can be somewhat irregu-

Figure 16. A 1.34 ct Vietnamese ruby. Photo by Robert Weldon/GIA.

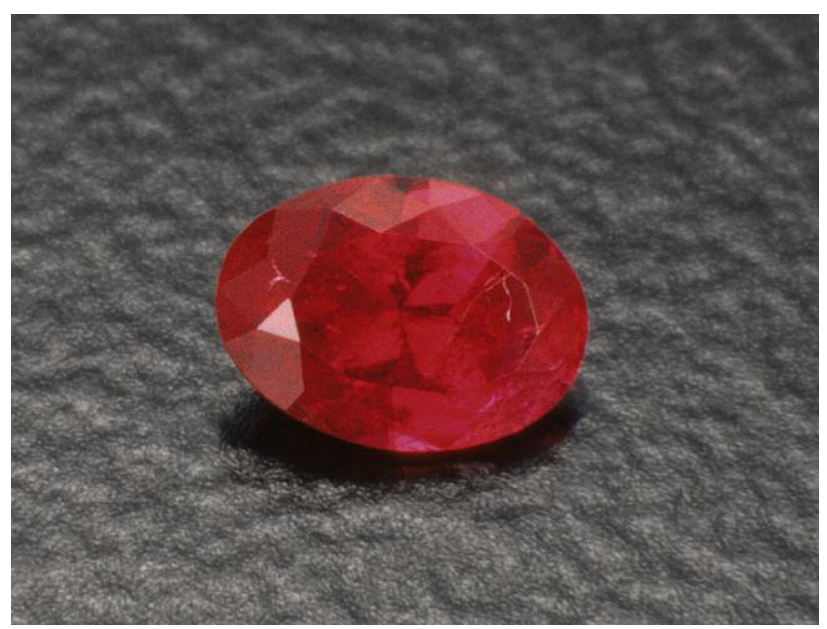




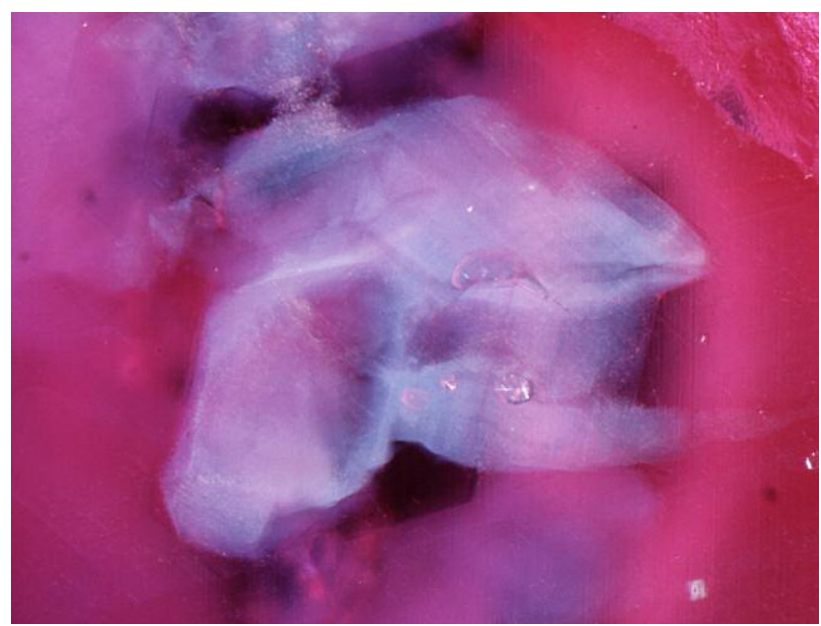

Figure 17. Dense, milky clouds distinguish this Vietnamese ruby from the rubies found in Mogok, Myanmar. Photomicrograph by GIA; field of view $1.75 \mathrm{~mm}$.

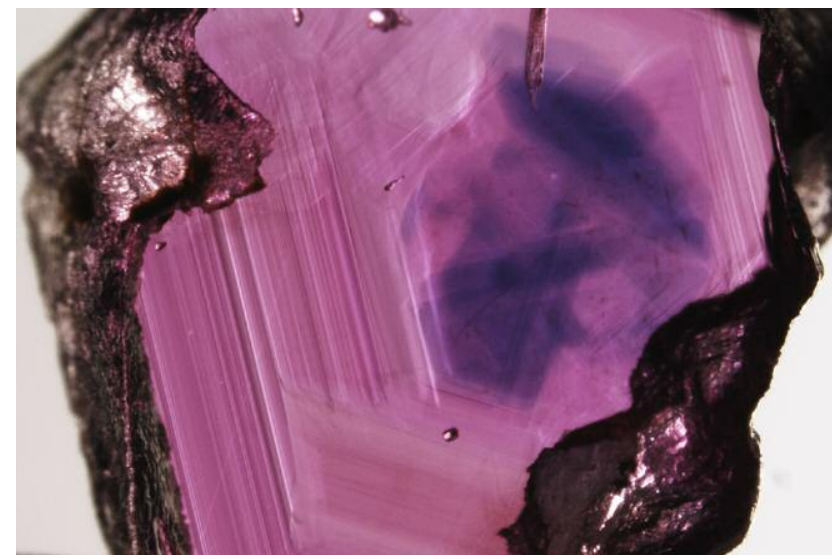

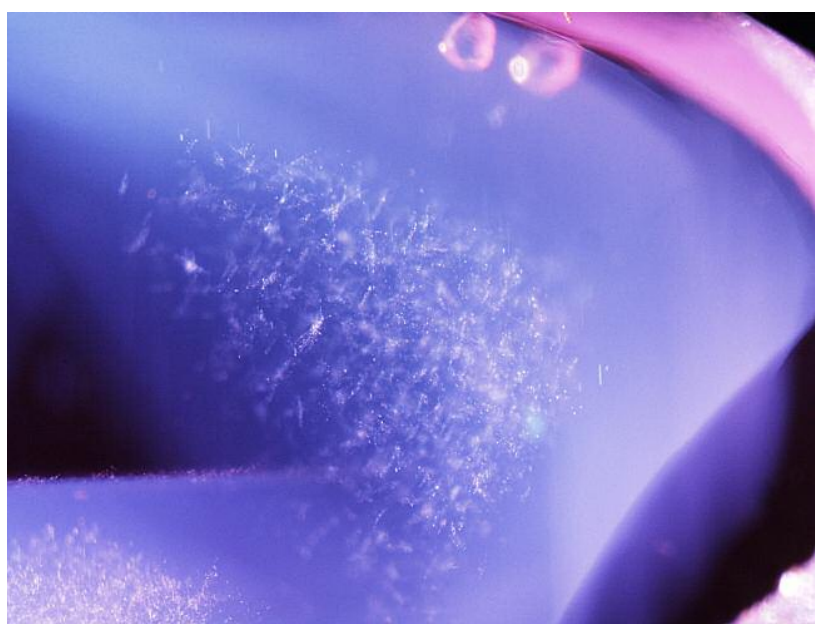

Figure 18. Coarse, patterned clouds and milky clouds provide strong evidence of this ruby's Vietnamese origin. Intense fiber-optic illumination produces the bluish coloration in this photo due to light scattering. Photomicrograph by GIA; field of view $2.33 \mathrm{~mm}$.

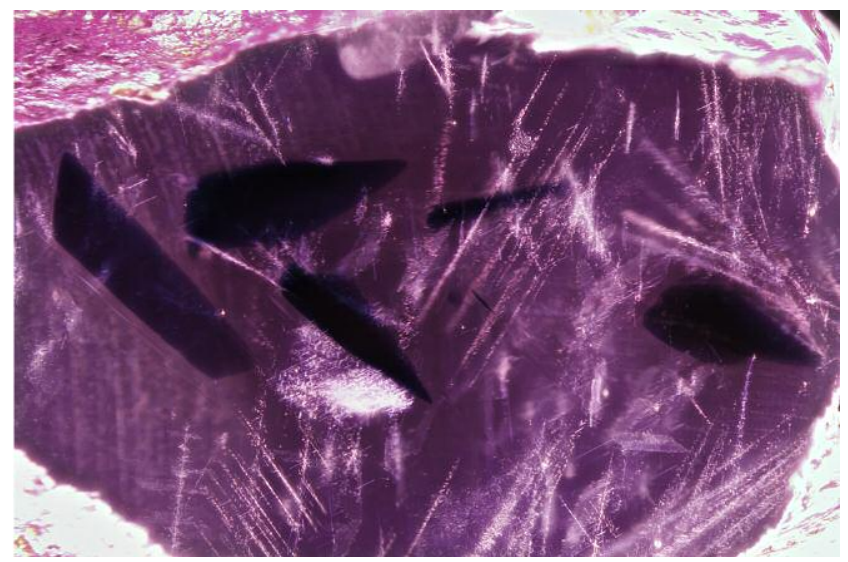

Figure 19. Blue color zoning is common in Vietnamese rubies. Photomicrographs by GIA (left, field of view $7 \mathrm{~mm}$ ) and Jonathan Muyal (right, field of view $3.57 \mathrm{~mm}$ ).

lar in nature (figure 19), as well as roiled growth patterns in some stones. Heat treatment is often used in an attempt to remove blue color zoning in these rubies, but this is often at a low enough temperature that a stone's silk may not be dramatically affected. Rounded mineral crystals can also be seen in Vietnamese rubies, although these are not considered diagnostic (figure 20).

Figure 20. Rounded mineral inclusions similar to those found in rubies from Mogok can be seen in Vietnamese rubies. In this example, the Vietnamese origin is corroborated by dense, milky clouds. Photomicrograph by GIA; field of view $1.4 \mathrm{~mm}$.

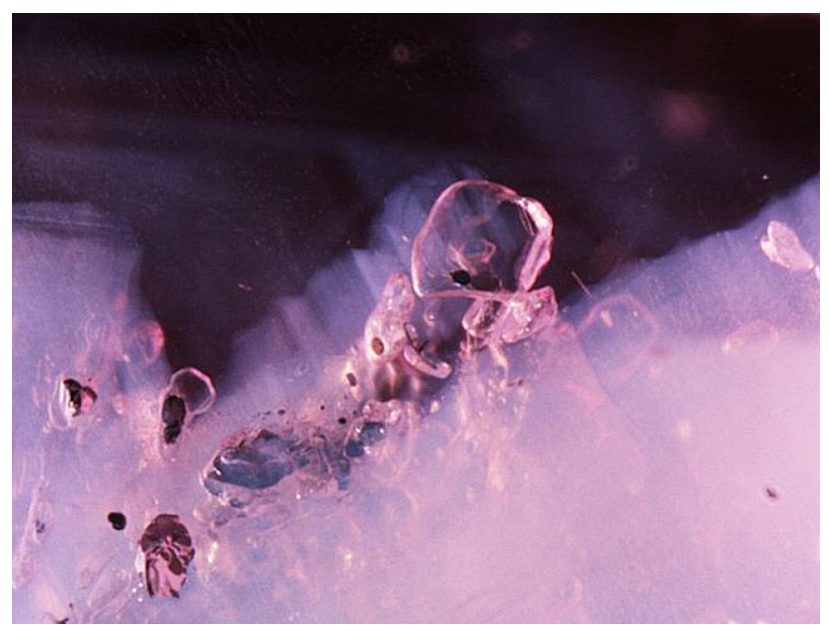




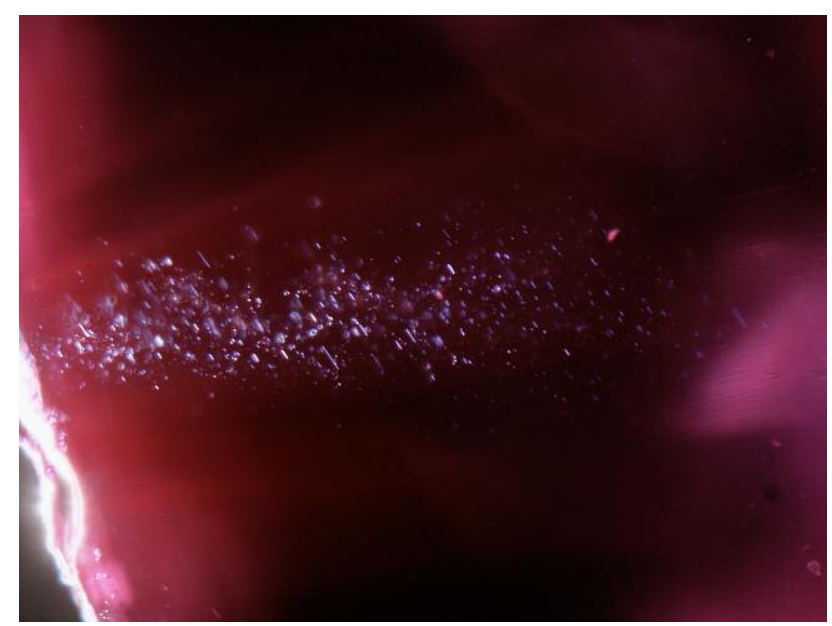

Figure 21. Short, thin rutile needles are also characteristic of Afghan rubies and may offer an indication of origin, along with other corroborating gemological data. Photomicrograph by Charuwan Khowpong; field of view $1.02 \mathrm{~mm}$.

The Internal World of Afghan Rubies. The ruby mines near Jegdalek in Afghanistan are considered one of the classic sources from the ancient world, believed to date back around 800 years (Bowersox et al., 2000). However, supplies have always been limited, especially for rubies with high clarity that could compete with fine rubies from Myanmar. The dominant inclusions in much of the material available are fractures and fingerprints. Unfortunately, high-quality material with sufficient clarity has been difficult to obtain, which has limited thorough study of the characteristic inclusions in this material. The following discussion will detail the information gathered so far

Figure 23. Afghan rubies can contain faint planar milky bands. Photomicrograph by Charuwan Khowpong; field of view $2.00 \mathrm{~mm}$.

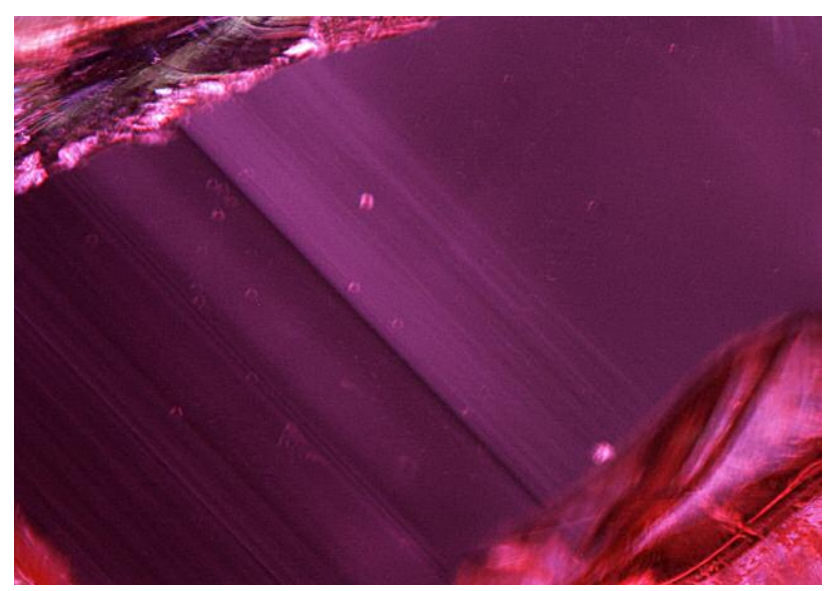

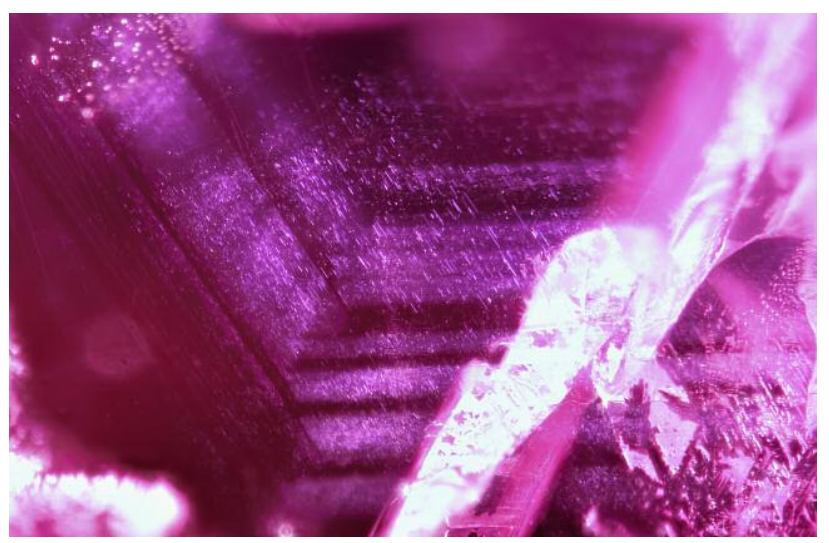

Figure 22. Fine particulate clouds arranged in a hexagonal pattern are often seen in Afghan rubies. Photomicrograph by Jonathan Muyal, field of view $1.8 \mathrm{~mm}$.

by GIA's field gemology program. Afghan rubies can sometimes be distinguished by characteristic fine rutile needles (figure 21) and fine particulate clouds, often found in angular or hexagonal patterns (figure 22), which are distinct from the milky clouds found in Vietnamese rubies or the coarser and needle-like silk seen in Mogok rubies. Planar milky clouds can also be found in Afghan rubies (figure 23), but they tend to be fainter than those seen in Vietnamese rubies and are not easily observed without fiber-optic illumination. Stringer-type inclusions formed of small dusty particulates are sometimes seen in Afghan rubies (figure 24), but they are also found in rubies from

Figure 24. Stringer inclusions are also common in Afghan rubies. Photomicrograph by Charuwan Khowpong; field of view $3.1 \mathrm{~mm}$.

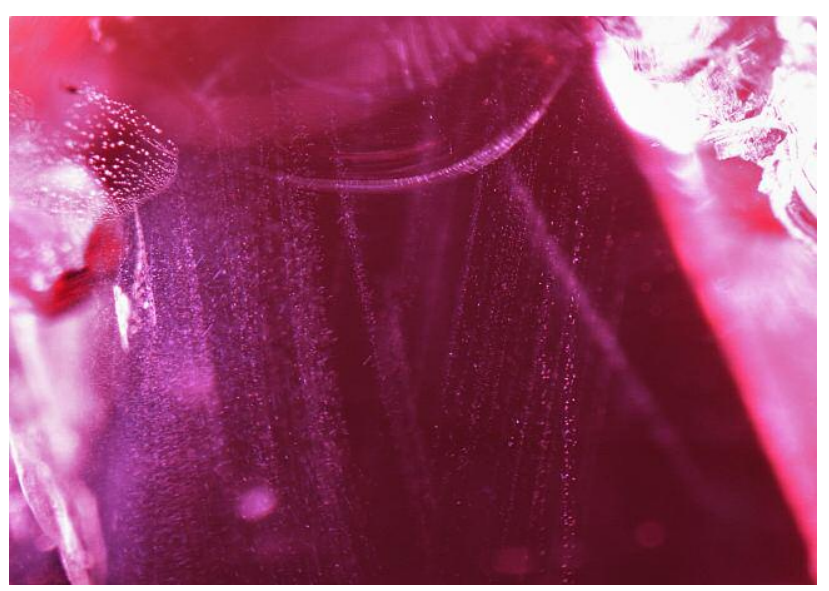




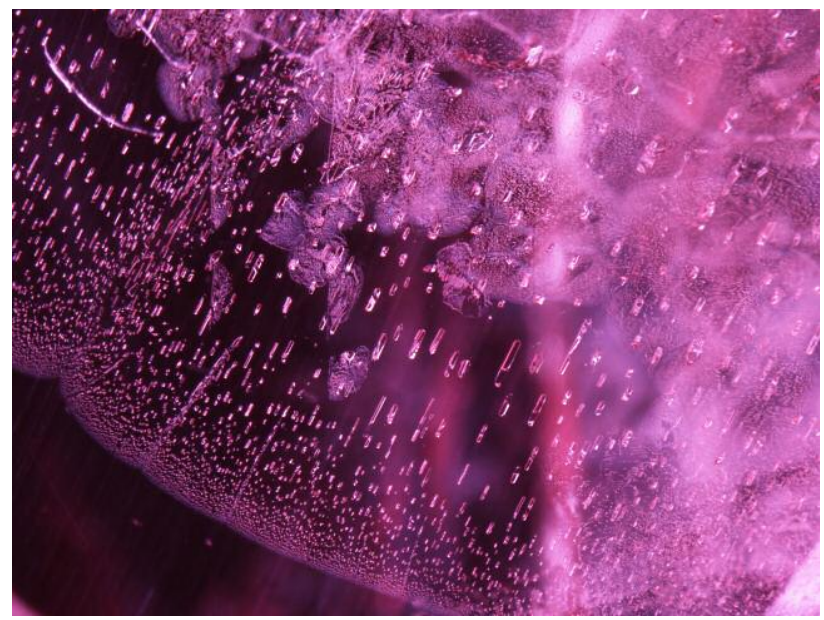

Figure 25. Fluid-filled fingerprints are often present in rubies from Afghanistan. Photomicrograph by GIA; field of view $3.1 \mathrm{~mm}$.

Tajikistan. Fluid-filled fingerprints are also seen in Afghan rubies and (figure 25).

The Internal World of Tajik Rubies. Tajik rubies are another relative newcomer to the world ruby mining scene (figure 26). Discovered in the 1970s by Soviet geologists, only small quantities have been produced from the Snezhnoe deposit in southern Tajikistan near the Chinese border (Smith et al., 1998; Sorokina et al., 2015). Further, much of what is produced has been heavily included, lower-quality material. Nonetheless, some very fine rubies are known to have been sourced from Snezhnoe. Tajik rubies can be difficult to sepa-

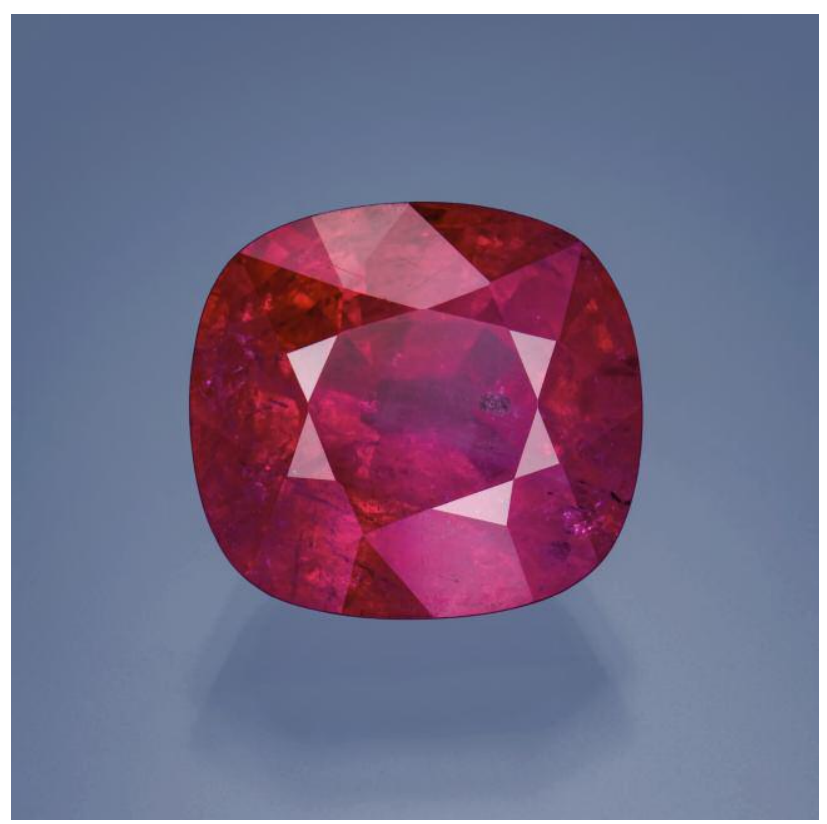

Figure 26. A 17.14 ct Tajik ruby. Photo by Robert Weldon/GIA; courtesy of Arthur Groom.

rate from other marble-hosted deposits, partly due to the relative lack of diagnostic inclusions. Much like Afghan rubies, the dominant inclusions are fractures and healed fissures (fingerprints). Also notable, and indicative of a Tajik origin, are so-called rosettes or haloes surrounding small crystal inclusions (figure 27). Blue color zoning is also frequently seen in Tajik rubies (figure 28). It can be distinguished from similar features observed in Vietnamese rubies by the angular

Figure 27. Small crystal inclusions with surrounding "rosettes" or haloes point to these rubies' Tajik origin. Photomicrographs by GIA; field of view $1.00 \mathrm{~mm}$ (left and right).
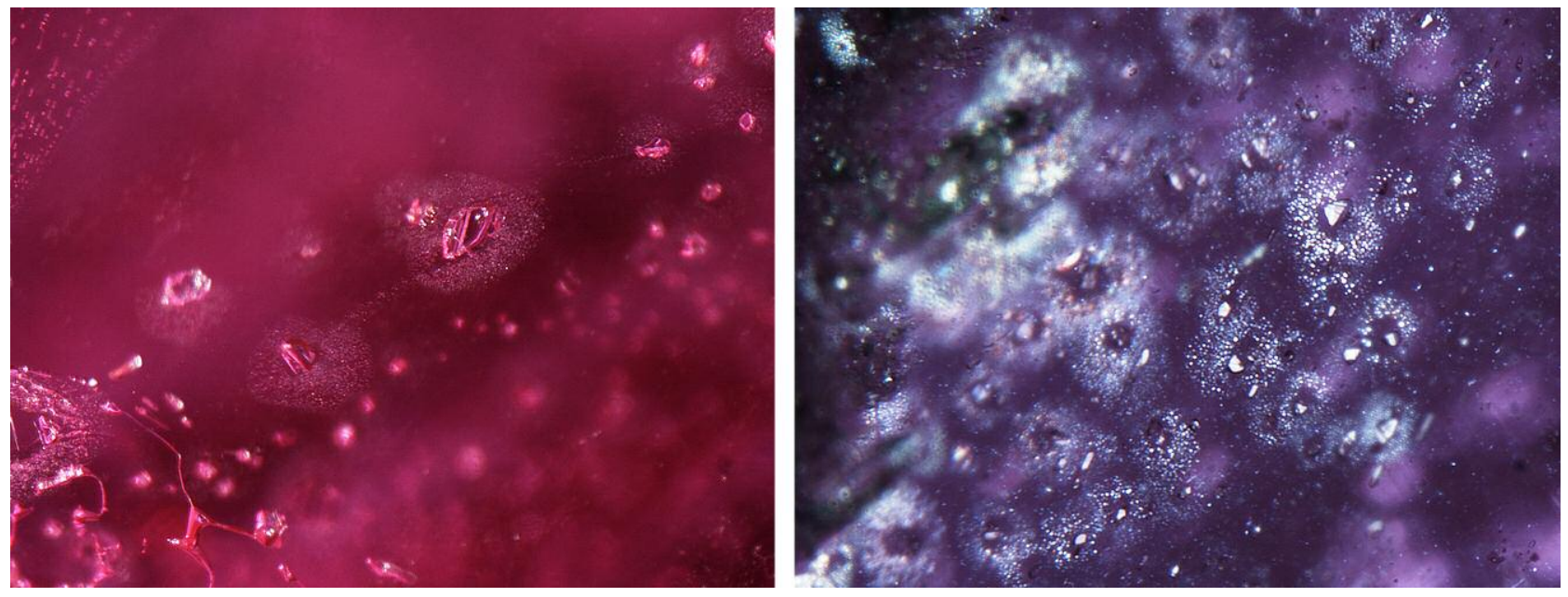


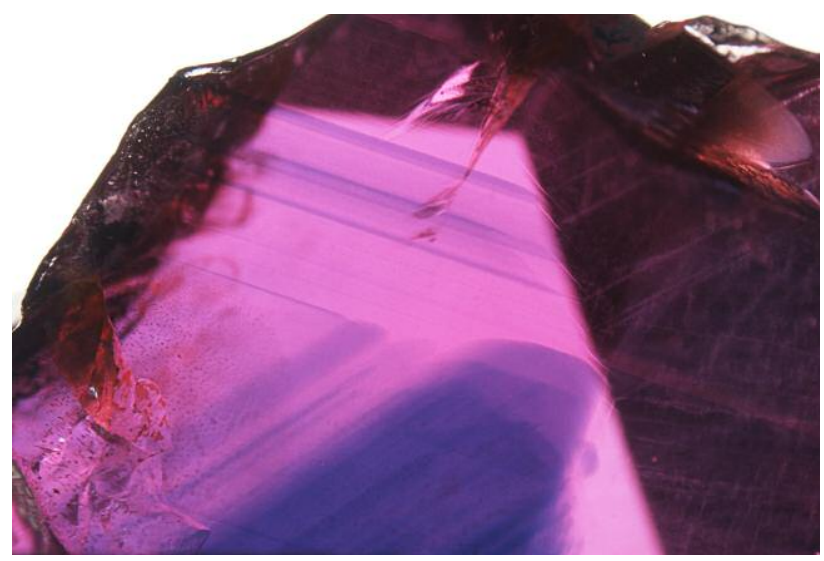

Figure 28. Blue color zoning in Tajik rubies is generally distinguished from similar features in Vietnamese rubies by its angular and more regular morphology. Photomicrograph by GIA; field of view $6.20 \mathrm{~mm}$.

and very planar nature of the blue zones, in contrast to the more irregular blue zoning in Vietnamese rubies. Tourmaline crystal inclusions seem to be a diagnostic mineral inclusion in Tajik rubies (figure 29). These tourmaline inclusions are often found in small, irregular clusters that include mica and graphite inclusions. Also observed are fine, dusty distributions of particles (figure 30) and sometimes stringer inclusions composed of fine particulate matter (figure 31). However, similar features are seen in Afghan rubies.

Inclusion Scenes Gone Wrong. With geographic origin determinations for marble-hosted rubies, one en-

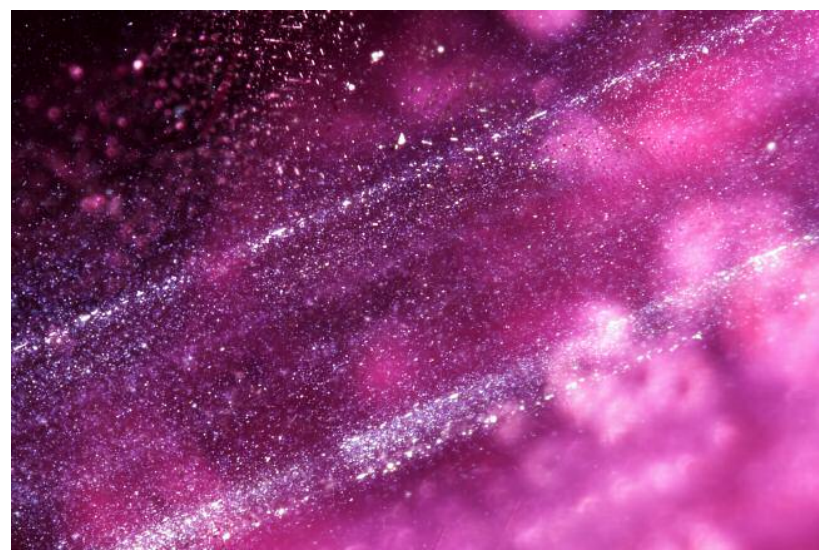

Figure 30. Small, often dusty groups of particles without a well-defined geometric pattern can be observed in Tajik rubies, but they may be difficult to distinguish from those seen in Afghan rubies. Photomicrograph by Charuwan Khowpong; field of view $2.5 \mathrm{~mm}$.

counters the same problem as with metamorphic blue sapphires: The gems from these deposits were mostly formed in the same geological orogenic event, from very similar geological formations, and likely at similar conditions of pressure, temperature, and chemistry. For this reason, there tends to be significant overlap in their gemological properties, namely inclusions and trace element chemistry. Care needs to be taken, especially with Vietnamese and Mogok rubies, as occasionally their inclusion scenes overlap. Importantly, Vietnamese rubies can sometimes be found with patterns of rutile silk that might give the initial impression of a Mogok origin. Inclusion

Figure 29. Tourmaline inclusions are sometimes found in Tajik rubies and can be used as an indication of their origin. Tourmaline is often observed as clusters accompanied by mica and graphite (right). Photomicrographs by Charuwan Khowpong; field of view $1.10 \mathrm{~mm}$ (left) and $1.69 \mathrm{~mm}$ (right).
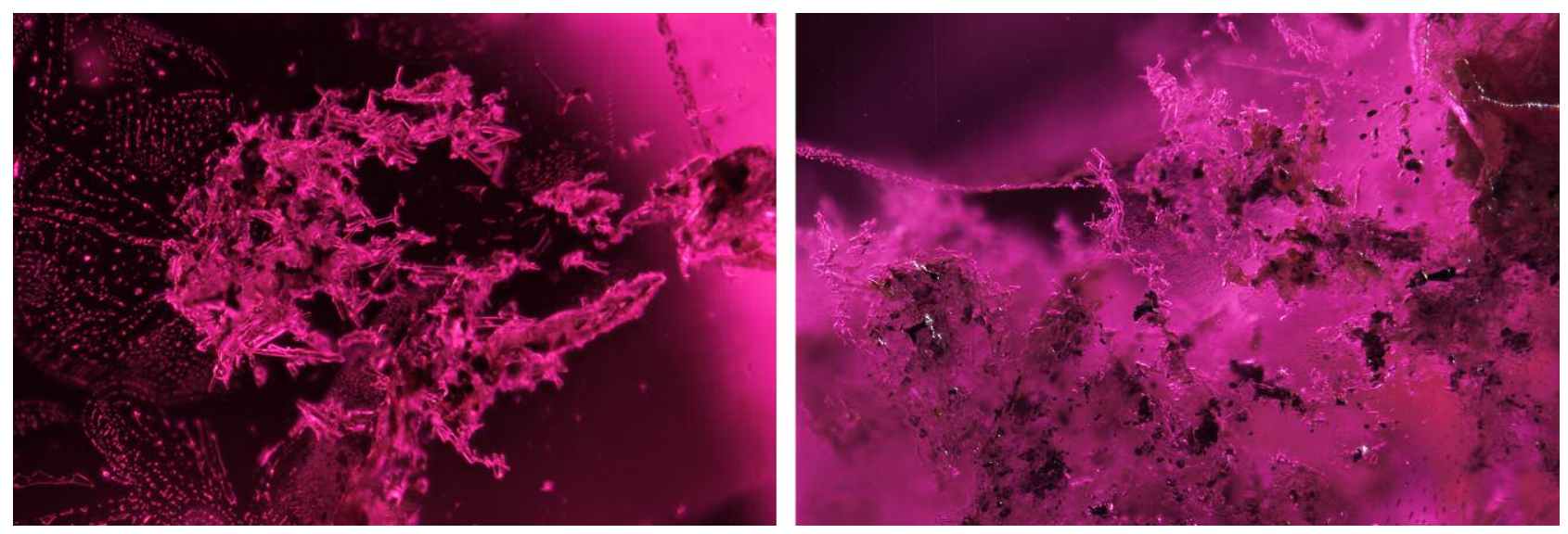


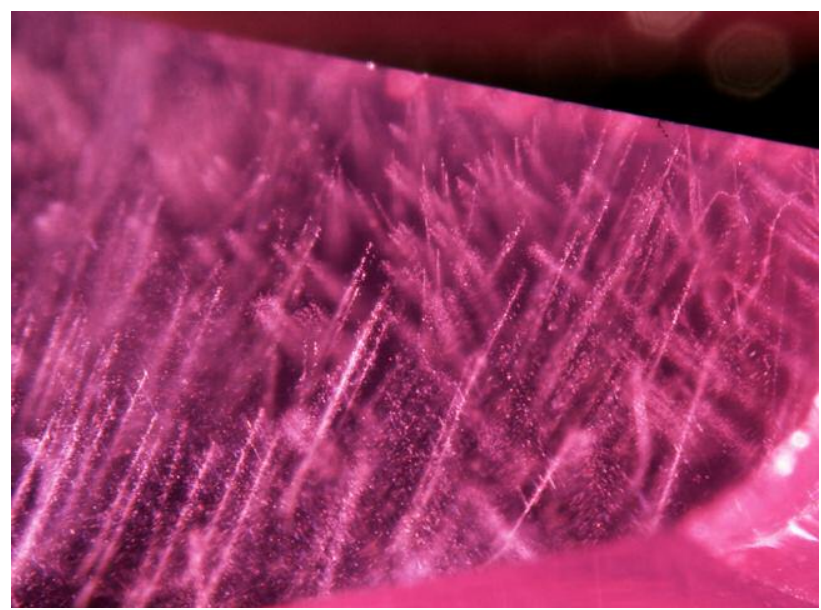

Figure 31. Stringer inclusions composed of minute particles can be seen in Tajik rubies as well as those from Afghanistan. Photomicrograph by Vararut Weeramonkhonlert; field of view $3.1 \mathrm{~mm}$.

scenes suggestive of Mogok rubies, composed of short to long well-defined needles of rutile silk (sometimes densely packed and intergrown) can occasionally be found in rubies from Vietnam (figures 32 and 33). Additionally, the roiled graining considered characteristic of Mogok rubies can also occasionally be found in Vietnamese rubies (figure 34). Observation of dense milky clouds, if present, might help to resolve overlap and indicate a Vietnamese origin. Other potentially conflicting inclusion scenes include the presence of patterned clouds in Tajik and Afghan rubies that might give an initial impression

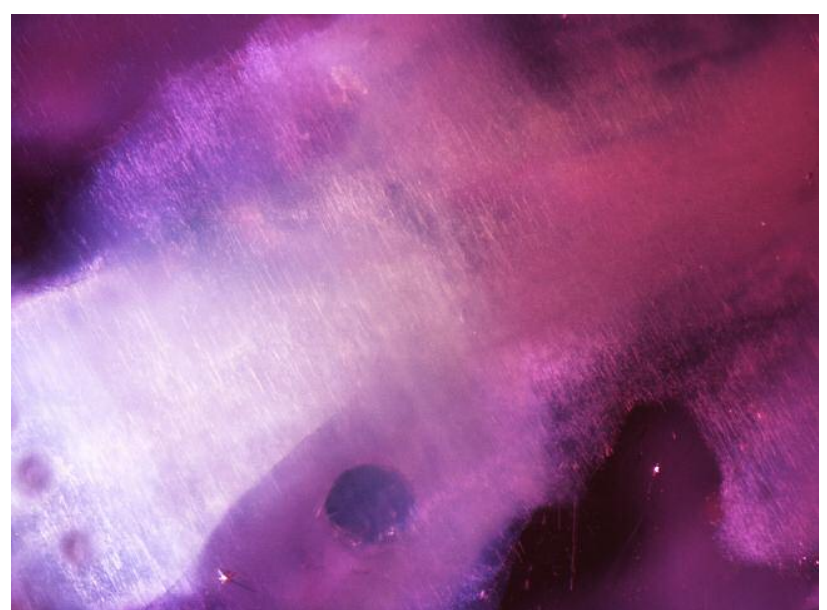

Figure 33. The dense, intergrown, and nested nature of the rutile silk might suggest a ruby mined in the Mogok Valley, potentially masking its true Vietnamese origin. Photomicrograph by GIA.

of a Vietnamese ruby (figures 35 and 36). Whenever possible, additional gemological evidence should be sought out to corroborate an origin conclusion. For instance, milky clouds might suggest a Vietnamese origin or arrowhead rutile needles might indicate a Mogok origin. However, it bears emphasizing that the gemological world is not perfect. Not every faceted stone will contain inclusion scenes that are diagnostic of a particular locality. Moreover, many stones do not have inclusion scenes that are even suggestive of one origin over another. A marblehosted ruby may lack milky or patterned clouds and

Figure 32. The short to long well-defined rutile silk in these Vietnamese rubies might give a mistaken impression of Burmese origin. Photomicrographs by GIA; field of view $1.10 \mathrm{~mm}$ (left) and $0.97 \mathrm{~mm}$ (right).
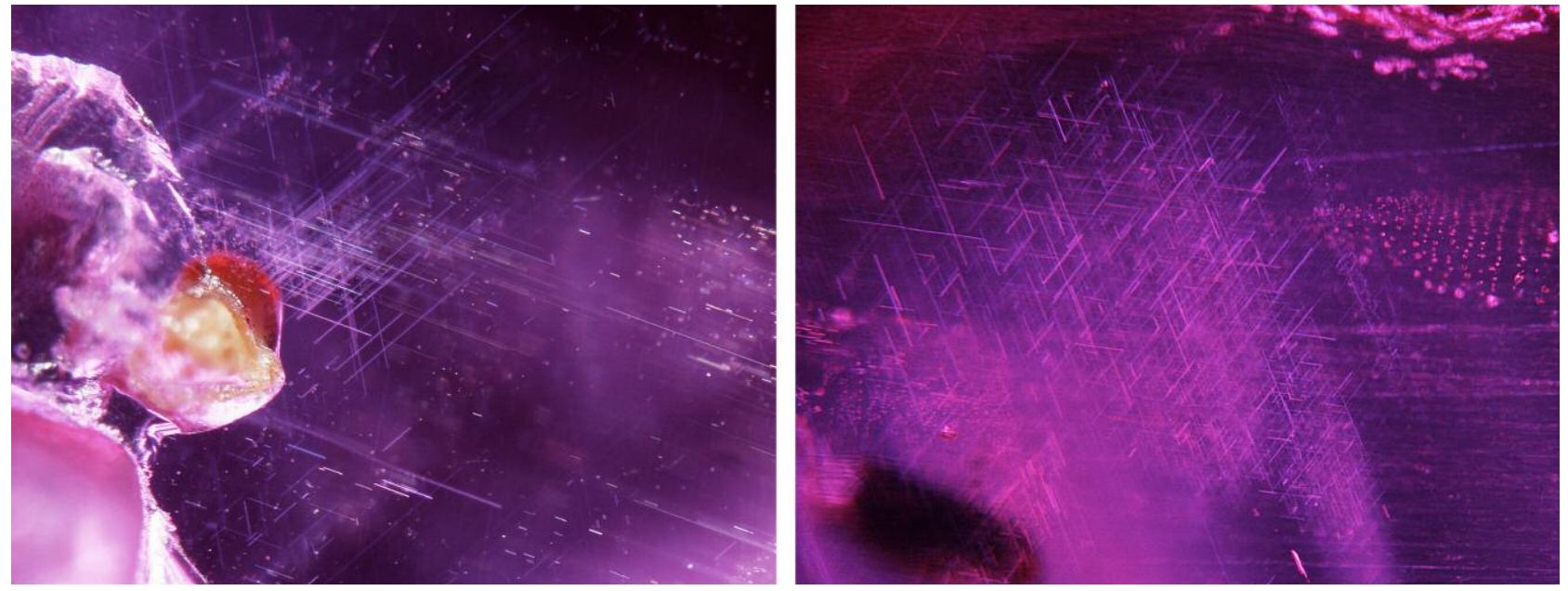


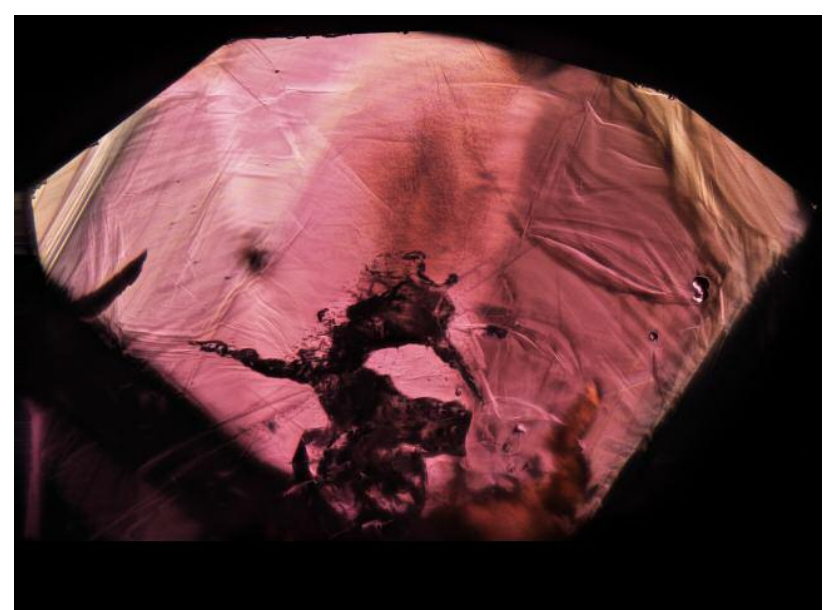

Figure 34. Roiled graining, sometimes suggestive of a Mogok origin, is occasionally observed in rubies from Vietnam. Photomicrograph by Jonathan Muyal; field of view $2.90 \mathrm{~mm}$.

contain only coarse rutile silk that is not particularly nested and dense, and not iridescent. In this case, the inclusion scene could give the impression of either a Burmese or Vietnamese origin, offering scant evidence to indicate one origin over another. In these cases, the only clear choice is to offer an "inconclusive" origin determination. Unfortunately, there will always be stones for which laboratories will be obligated to issue "inconclusive" calls due to the lack of any diagnostic piece of evidence pointing toward a specific conclusion.

Figure 36. The patterned clouds in this Tajik ruby might also suggest a Vietnamese origin in the absence of any additional origin evidence. Photomicrograph by GIA; field of view $6.30 \mathrm{~mm}$.

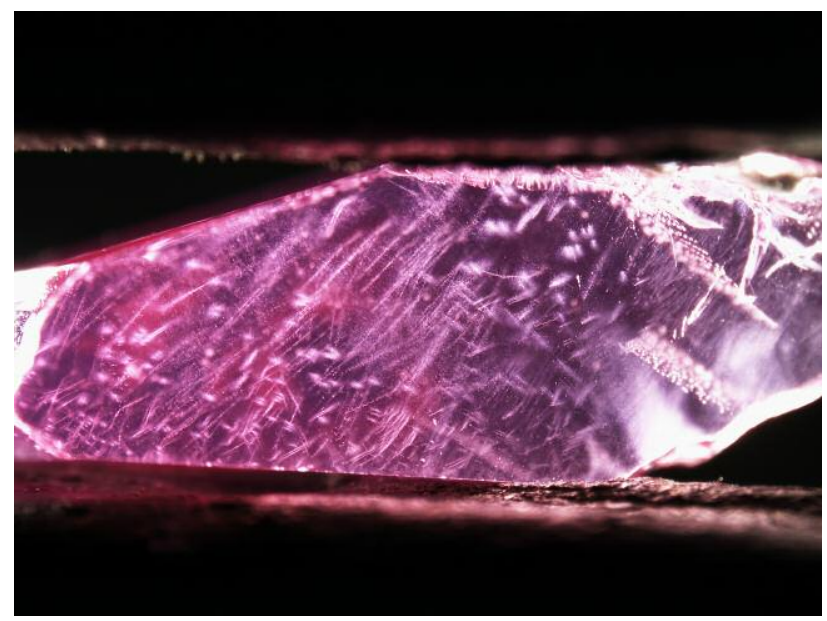

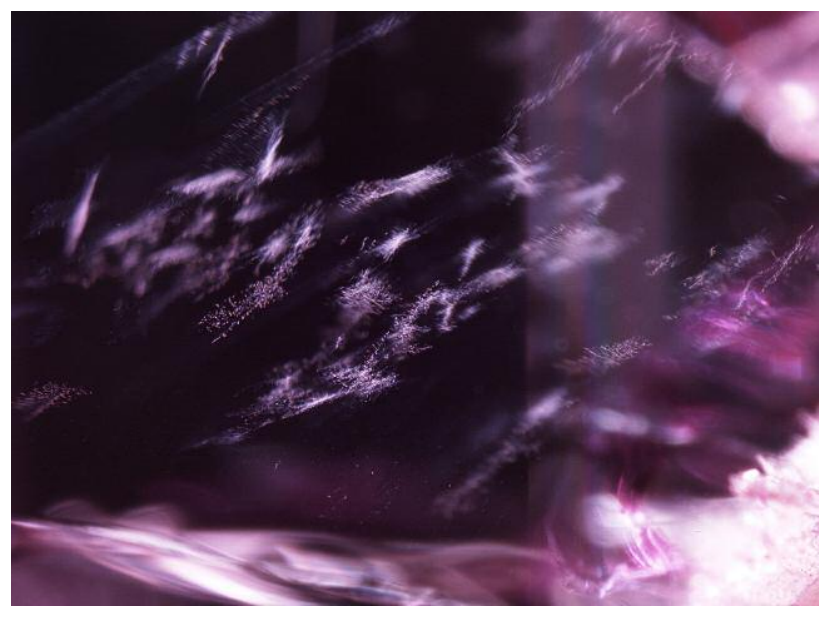

Figure 35. The snowflake-like patterned clouds in this Afghan ruby might otherwise suggest a Vietnamese origin. Other gemological evidence would be needed to issue a conclusive origin determination. Photomicrograph by Charuwan Khowpong; field of view $2.04 \mathrm{~mm}$.

High-Iron Ruby Inclusions. If trace element analysis places a stone in the high-iron ruby group, the geographic origin determination process follows a different path from marble-hosted rubies, with a distinct set of possible provenances. These are rubies from Thailand and Cambodia, Madagascar, Mozambique, and smaller deposits in Tanzania, Kenya, and Greenland. Fortunately, "high-iron ruby" is more of a broad catchall term with relatively loose implications about geological conditions of formation. For instance, highiron rubies from Mozambique and Madagascar formed during high-pressure and high-temperature regional metamorphism, while those mined near the Thai/Cambodian border are basalt-related and, in some ways, more geologically akin to classic magmatic blue sapphires. The common thread seems to be the rubies' derivation from similar host rocks. While there are many open questions about their exact geological genesis, high-iron rubies are generally considered to have been derived from what were originally basic or (ultra)mafic igneous rocks. Nonetheless, variations in the specific geological circumstances surrounding ruby genesis have produced differences in their gemological properties, allowing for straightforward origin determination in most cases.

Rubies from most of the high-iron ruby deposits (Mozambique, Madagascar, and Thailand/Cambodia) can often be separated based only on inclusions, but even if microscopic observations fail to produce a conclusion, trace element chemistry can almost always provide the final piece of evidence. In the following section we will describe typical inclusion scenes for 


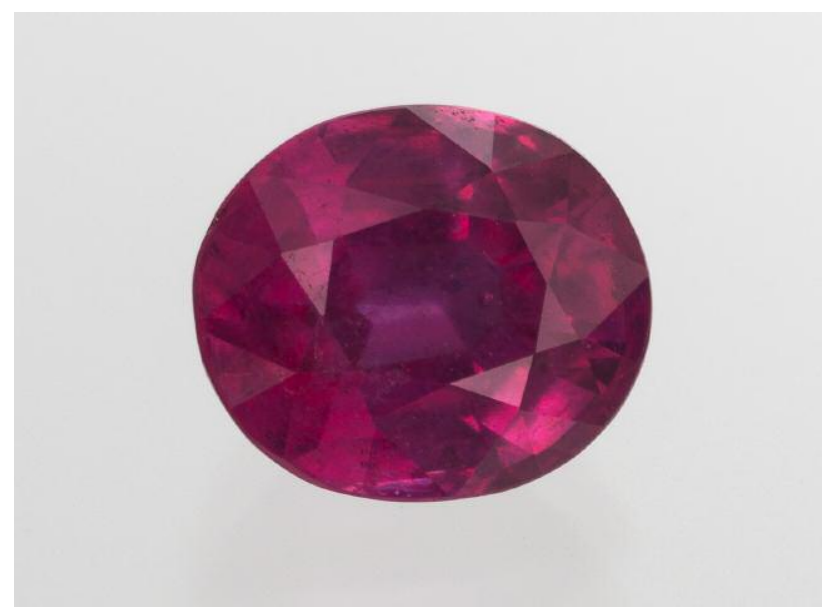

Figure 37. A 3.90 ct Cambodian ruby. Photo by Orasa Weldon.

the major high-iron ruby deposits. Additional information can be obtained from the following references (Schwarz and Schmetzer, 2001; Gübelin and Koivula, 2008; Pardieu et al., 2012; Hughes et al., 2015, 2017; Vertriest and Saeseaw, 2019).

The Internal World of Thai/Cambodian Rubies. Rubies were mined in the ancient kingdom of Siam, along the present-day Thai/Cambodian border, for hundreds of years (figure 37). Until relatively recently, these Siamese rubies were the only serious alternative to those mined in Mogok. Back then it would have been straightforward to separate them from Mogok rubies, and even today the Thai/Cambodian rubies are easy to identify. Note, however, that rubies from the Chanthaburi-Trat area in Thai-

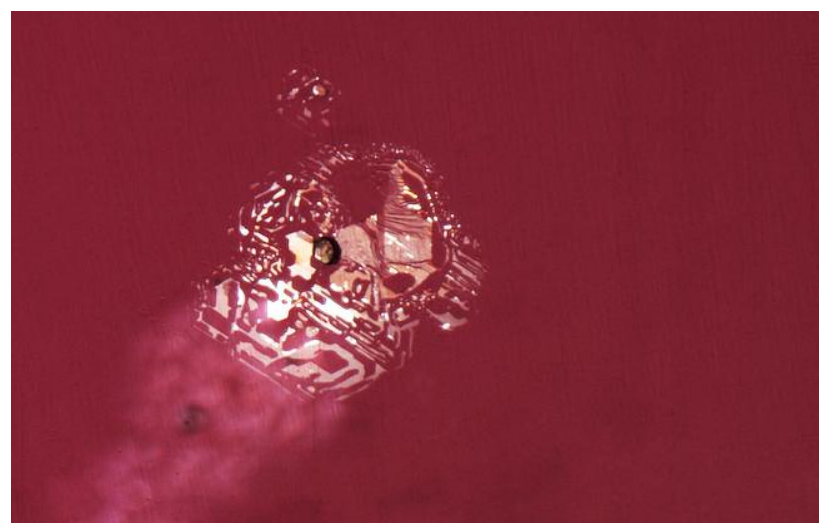

Figure 38. The geometric, partially healed decrepitation halo surrounding this negative crystal provides evidence of Cambodian provenance. Photomicrograph by Jonathan Muyal; field of view $0.95 \mathrm{~mm}$.

land are virtually identical to those found just across the border in Pailin, Cambodia, as the mining area is essentially one single deposit that straddles this geographic border (Sangsawong et al., 2017). One of the most striking microscopic features of Thai/Cambodian rubies is their lack of any rutile silk. The most prominent features are negative crystals, melt inclusions, and voids with partially healed decrepitation haloes that show geometric patterns and iridescent colors when using fiber-optic illumination (figures 38 and 39). These haloes are all oriented in the same crystallographic direction and are very transparent when light is not being reflected off them. When the correct angle is found in the microscope, they all

Figure 39. The thin-film decrepitation haloes in Thai/Cambodian rubies tend to show iridescent interference colors when viewed with fiber-optic light. Photomicrographs by Jonathan Muyal (left, field of view $2.90 \mathrm{~mm}$ ) and John I. Koivula (right, field of view $4.10 \mathrm{~mm}$ ).
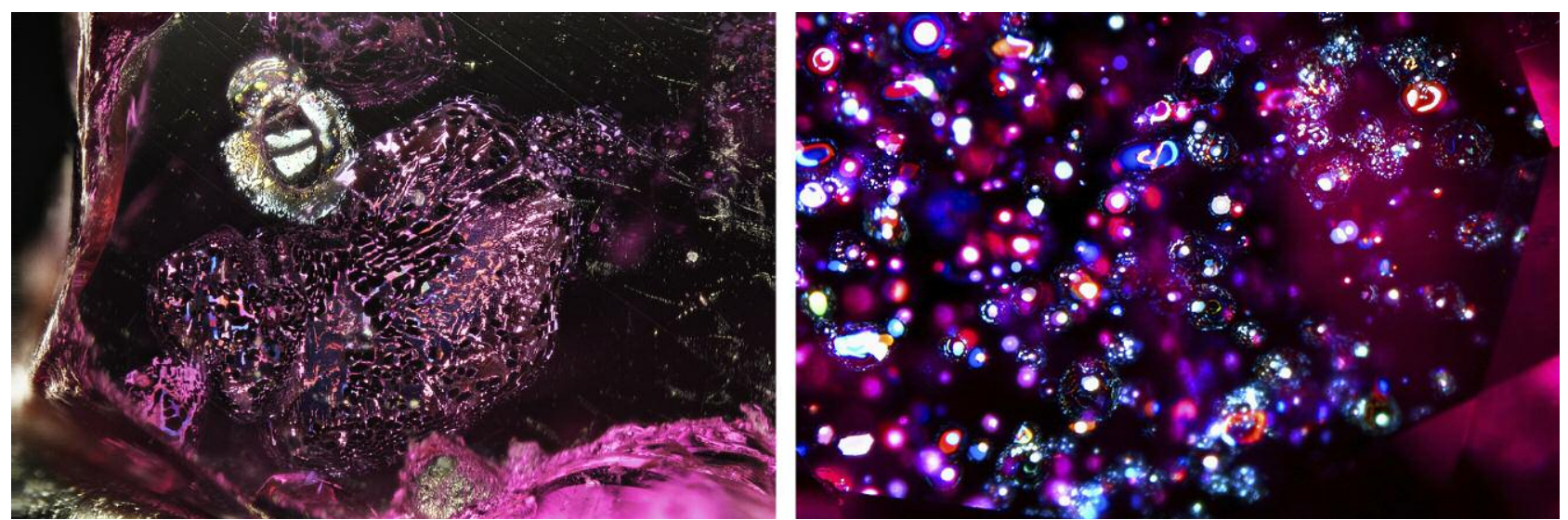


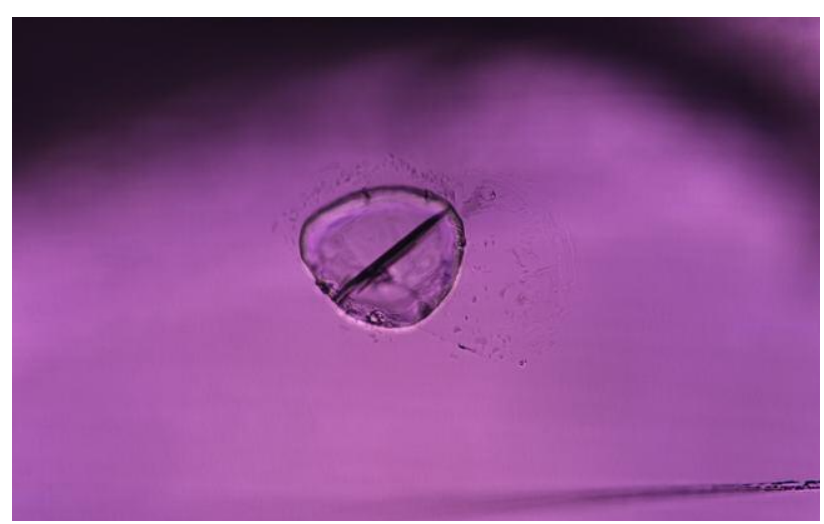

Figure 40. Diopside inclusions are a characteristic, if rarely encountered, inclusion in Thai/Cambodian rubies. Photomicrograph by Aaron Palke; field of view $0.71 \mathrm{~mm}$.

light up at once, sometimes with colorful displays of iridescence. Also seen are similar reflective platelettype inclusions, which are ostensibly not centered around a larger parent inclusion. Solid mineral inclusions are relatively uncommon but include diopside and rarely garnet or pyrrhotite (figure 40). Twinning is prevalent in Thai/Cambodian rubies, and the intersection tubules between twinned sectors are often filled with diaspore or other aluminum (oxy)hydroxides (figure 41). Note that Thai/Cambodian stones can almost always be identified in the lab by their signature inclusion scenes.

The Internal World of Mozambique Rubies. The rise of Mozambique in the early twenty-first century completely upended the global ruby market. Never before had such vast quantities of high-quality ruby (figure 42) been so freely available to the gem and jewelry industry. This could have resulted in a significant problem for the gemological laboratories had the Mozambique ruby not been fairly straightforward to identify (Vertriest and Saeseaw, 2019). In many cases, a Mozambique origin can be concluded based on observations of inclusion scenes, but additional evidence is always sought in the form of trace element chemistry, which almost always closes the case (see the "High-Iron Ruby Trace Element Chemistry" section below). Common mineral inclusions in Mozambique rubies are grayish green amphiboles (figure 43) and hexagonal mica booklets with stress fracture fringes (figure 44). Sulfide and spinel inclusions are also observed (figure 45). Mozambique rubies also can contain angular particulate clouds

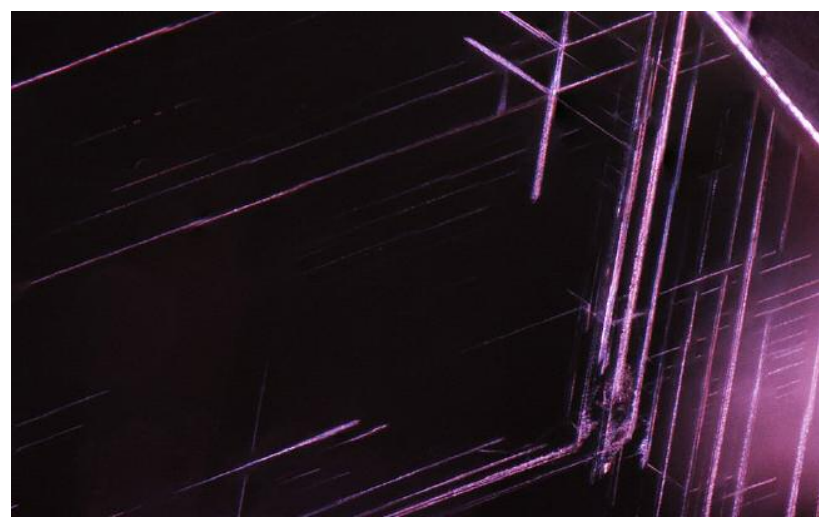

Figure 41. Twinning is relatively common in Thai/Cambodian rubies, and the intersection tubules between twinned domains are often filled with diaspore or other aluminum (oxy)hydroxides. Photomicrograph by Jonathan Muyal; field of view $1.03 \mathrm{~mm}$.

(figure 44, left), but they are more frequently identified by their characteristic fields of reflective, platelet-like particles (figures 46 and 47). Like the haloes seen in Thai/Cambodia rubies, these platelets are all oriented in the same crystallographic direction

Figure 42. Mozambique ruby, approximately $5 \mathrm{ct}$. Photo by Robert Weldon/GIA; courtesy of Amba Gem Corporation.

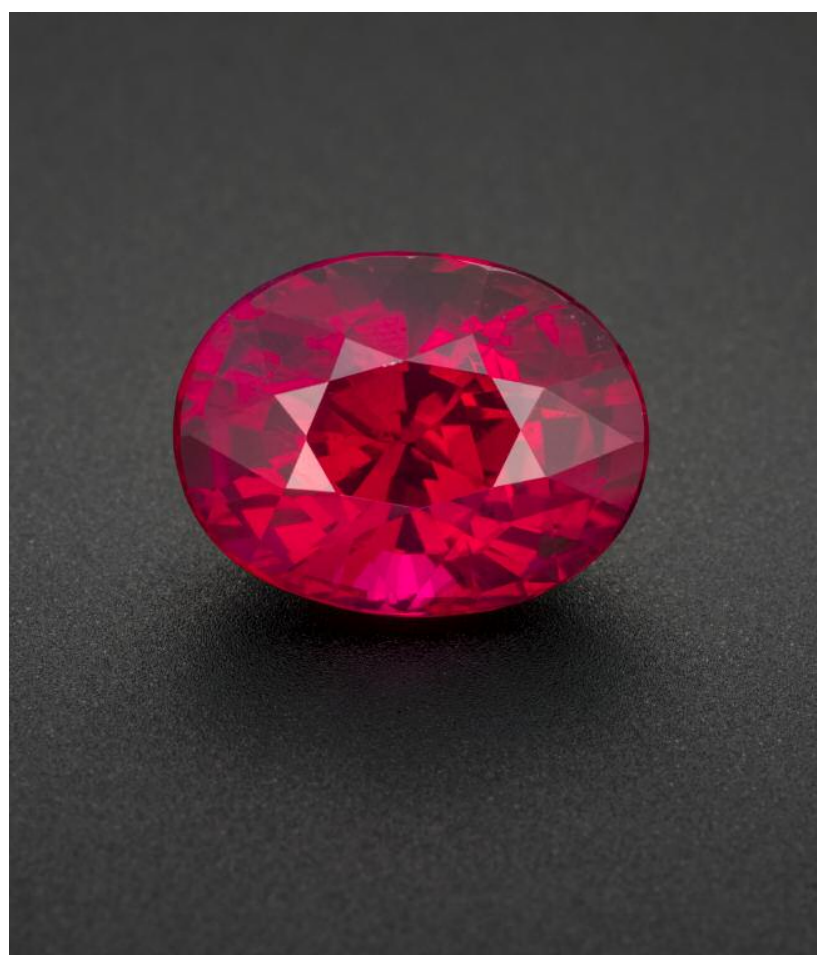




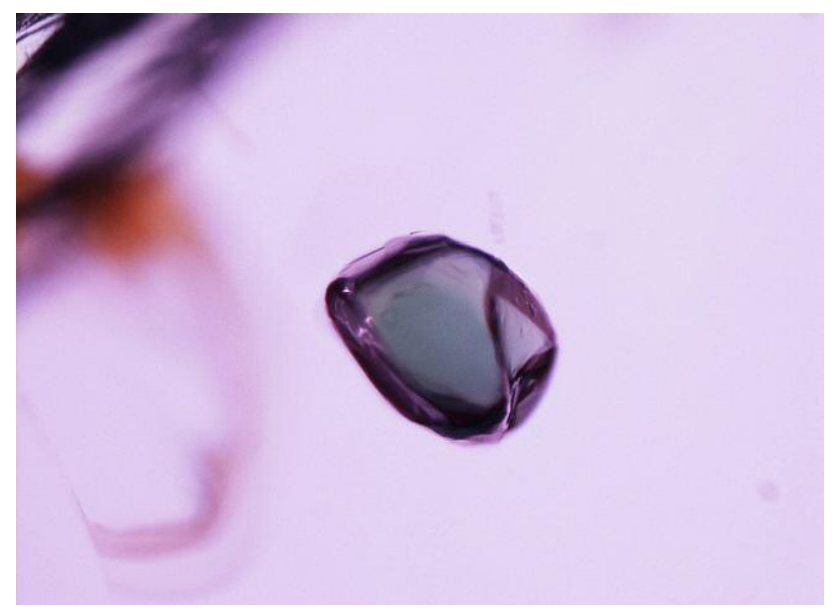

Figure 43. Grayish green amphiboles are one of the more common mineral inclusions in Mozambique rubies. Photomicrograph by Jonathan Muyal; field of view $1.32 \mathrm{~mm}$.

and may be difficult to see until that direction is found. Then they will all become visible at once. As with the rest of the high-iron rubies, Mozambique rubies can generally be identified in the lab by their inclusion scenes and trace element chemistry.

The Internal World of Madagascar Rubies. Madagascar rubies are the other East African newcomer in the ruby market (Schwarz and Schmetzer, 2001; Pardieu et al., 2012; Hughes et al., 2015). While they have never reached the commercial importance of Mozambique and much of the production is com-

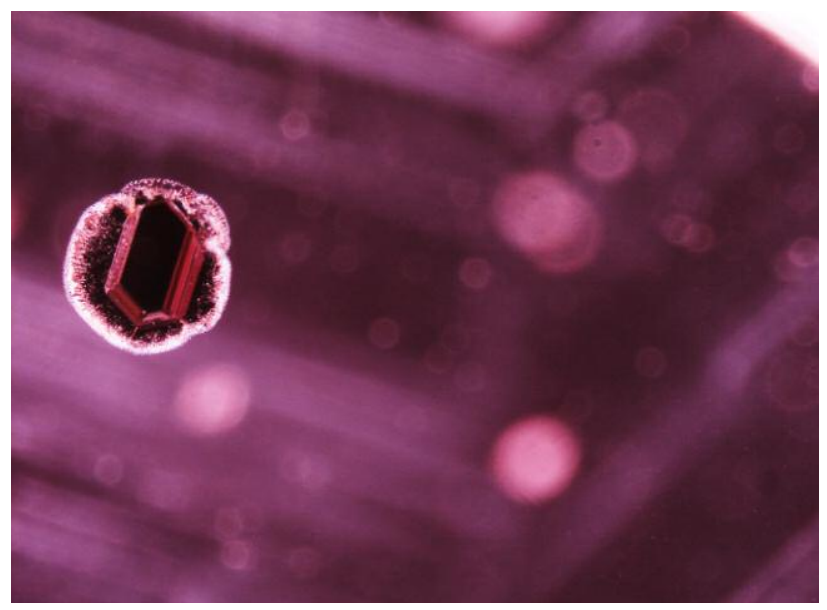

Figure 45. Sulfides are occasionally found as inclusions in Mozambique rubies. Photomicrograph by Jonathan Muyal; field of view $1.70 \mathrm{~mm}$.

mercial grade, some exceptional ruby has been derived from Madagascar. Gemologically and geologically, Madagascar's rubies are most similar to those from Mozambique. Muscovite inclusions are occasionally encountered in rubies from Madagascar (figure 48) as well as amphibole, which may generally have a distinctive morphology with longer, more prismatic rod-like crystals (figure 49). However, the more common and characteristic inclusion in rubies from Madagascar is zircon, especially widely distributed clusters of small, rounded zircons (figures 50 and 51). Blocky and prismatic orange, brown, or black

Figure 44. Muscovite inclusions with concentrically centered tension fractures are a common sight in Mozambique rubies. Photomicrographs by Jonathan Muyal; field of view $1.99 \mathrm{~mm}$ (left) and $1.26 \mathrm{~mm}$ (right).
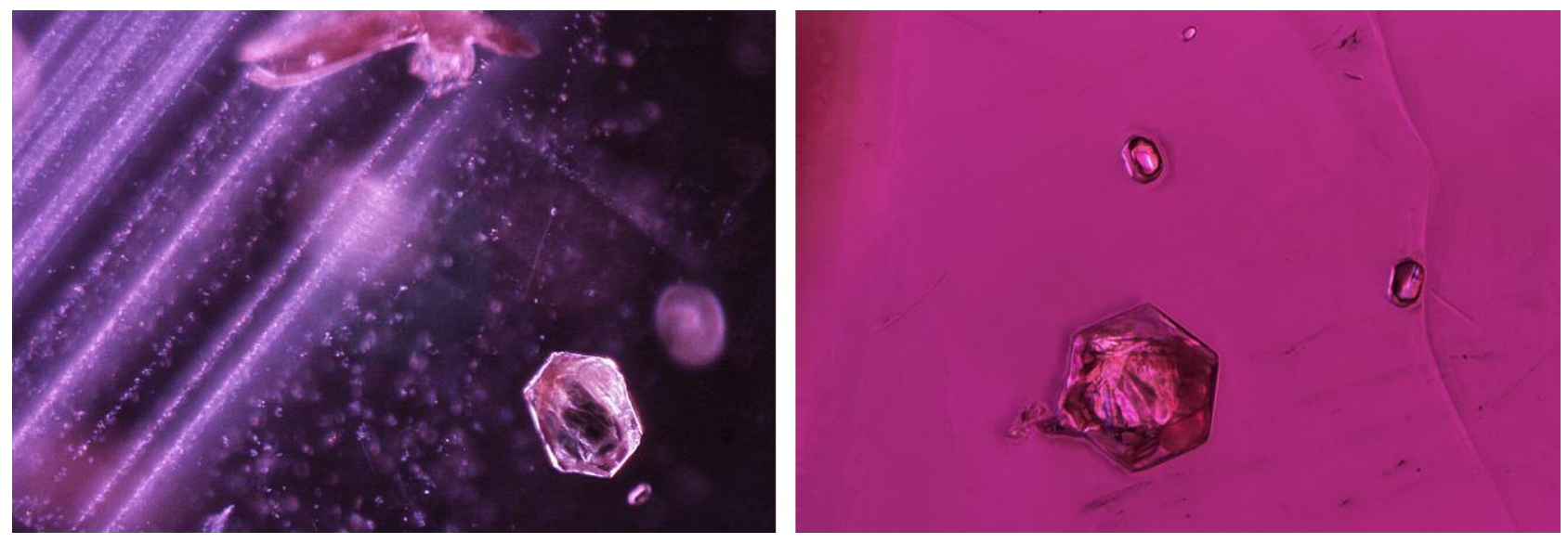


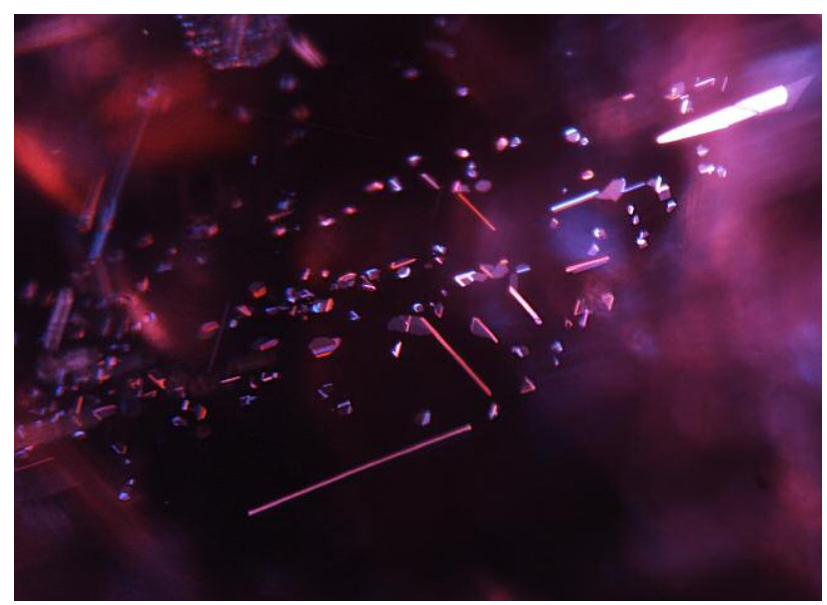

Figure 46. Platelet inclusions are one of the telltale signs of a Mozambique ruby. Photomicrograph by $B$. Kongsomart; field of view $0.70 \mathrm{~mm}$.

rutile inclusions can also be encountered and suggest a Madagascar provenance (figure 52). Particle clouds may be encountered as well, often composed of short needles and fine particulates, but sometimes mixed with long needles (figure 53). The particle clouds usually show a well-defined hexagonal arrangement, and there is the possibility of confusion with similar features seen in Mozambique rubies. Occasionally Madagascar rubies also host angular milky clouds, a feature not characteristic of the other major high-iron

Figure 48. Muscovite inclusions, as seen in this Madagascar ruby, can also be found in Mozambique rubies. These inclusions alone should not be used to determine a ruby's geographic origin. Photomicrograph by GIA; field of view $0.97 \mathrm{~mm}$.

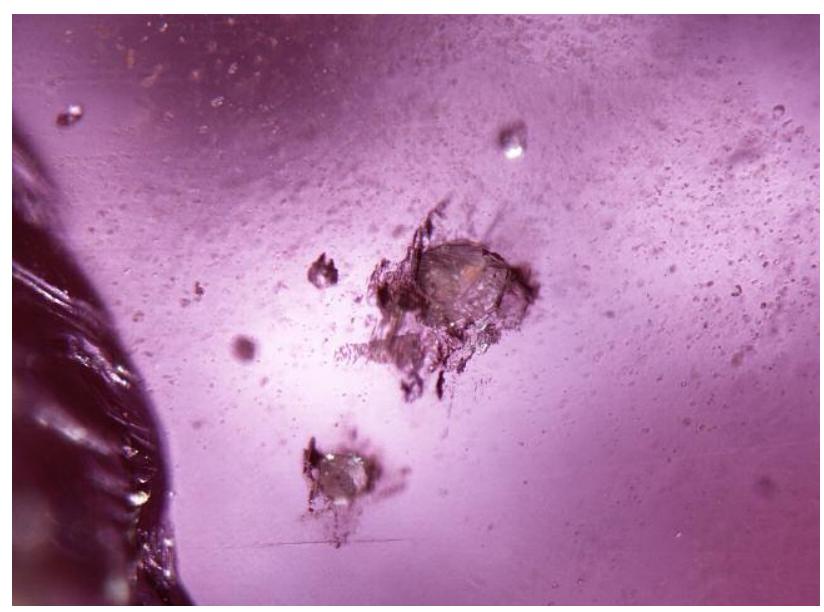

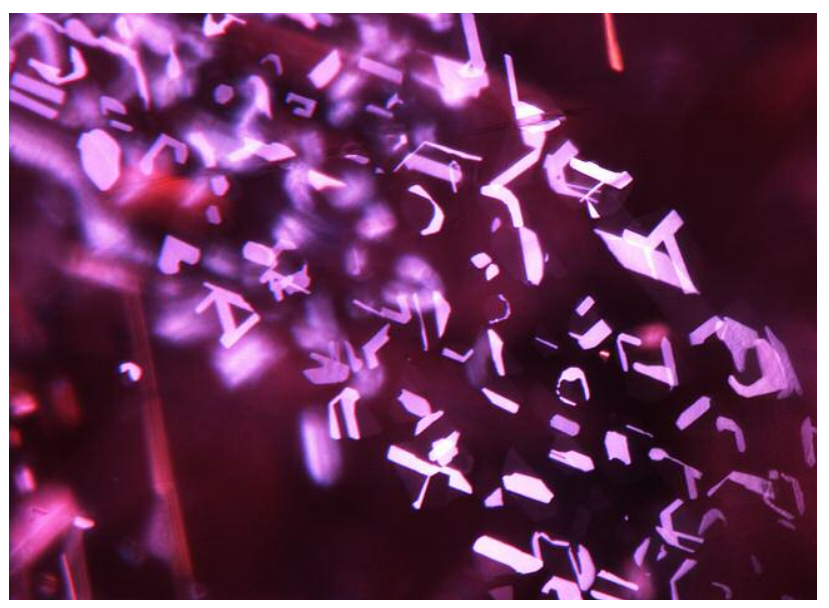

Figure 47. The field of platelet inclusions here is solid evidence of this ruby's Mozambique provenance. Photomicrograph by GIA; field of view $0.82 \mathrm{~mm}$.

ruby deposits. Madagascar rubies are generally easy to identify in the laboratory based on their inclusion scenes and trace element chemistry.

Trace Element Chemistry of Marble-Hosted Ruby. When attempting to use trace elements to discern a marble-hosted ruby's origin, one has the same problem encountered with metamorphic blue sapphires:

Figure 49. Amphibole inclusions are found in Mozambique as well as Madagascar rubies (shown here). In Madagascar rubies, amphibole tends to take on an elongate, rod-like morphology, although similar morphology can be encountered in Mozambique stones. Care should be taken when using these inclusions as an indicator of origin. Photomicrograph by Victoria Liliane Raynaud-Flattot; field of view $1.04 \mathrm{~mm}$.

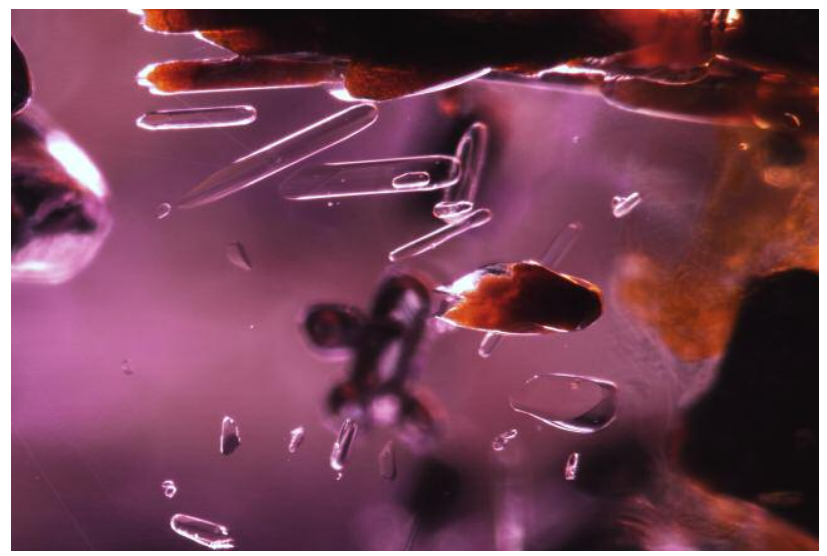




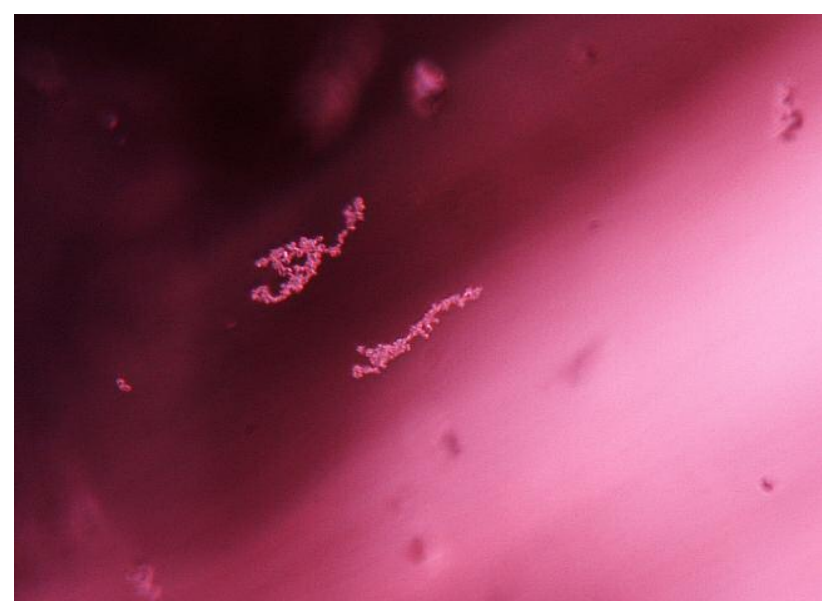

Figure 50. Clusters of small, rounded zircon crystals support a conclusive geographic origin determination for this Madagascar ruby. Photomicrograph by Patcharee Wongrawang; field of view $0.86 \mathrm{~mm}$

The very similar geological conditions of formation for these rubies creates very little deviation in their trace element profiles. When the compositional data are plotted together for the major economic deposits, separation can seem almost hopeless. The selective plotting method developed for blue sapphires (see Palke et al., 2019, pp. 536-579 of this issue) is also applied to origin determinations for marble-hosted rubies using the same suite of trace elements $(\mathrm{Mg}$, $\mathrm{Ti}, \mathrm{V}, \mathrm{Fe}$, and $\mathrm{Ga}$ ). The ranges of trace element pro-

Figure 52. Blocky, euhedral rutile crystal inclusions are a common sight in Madagascar ruby. Photomicrograph by Patcharee Wongrawang; field of view $1.95 \mathrm{~mm}$.

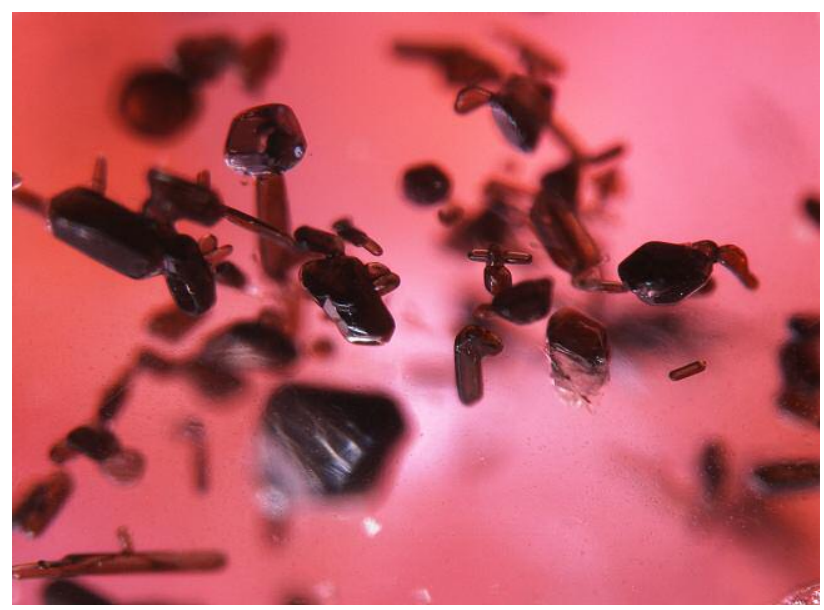

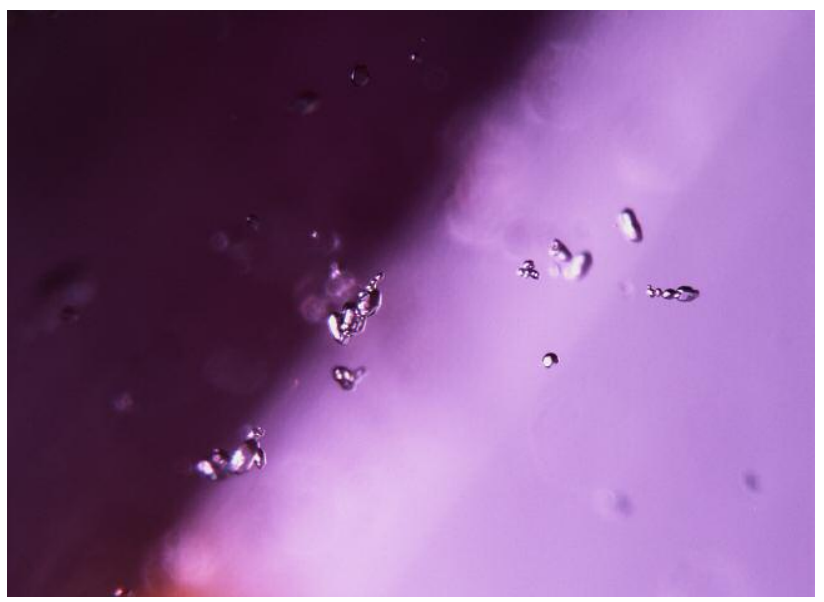

Figure 51. Madagascar rubies are often identified by clusters of small zircon crystals. Photomicrograph by Patcharee Wongrawang; field of view $1.56 \mathrm{~mm}$.

files seen in marble-hosted rubies can be found in table 1. By filtering out reference data with dissimilar trace element profiles and comparing an unknown stone only against reference stones that match the unknown, the trace element plots are greatly simplified, making it easier to interpret the data. In some cases, the selective plotting method is very useful for marble-hosted rubies and can provide evidence of a stone's provenance that would not have been obvious otherwise (figure 54). (Note that all trace element

Figure 53. Hexagonal particulate clouds composed of short and long rutile silk are a frequent observation in Madagascar rubies. Photomicrograph by Patcharee Wongrawang; field of view $1.20 \mathrm{~mm}$.

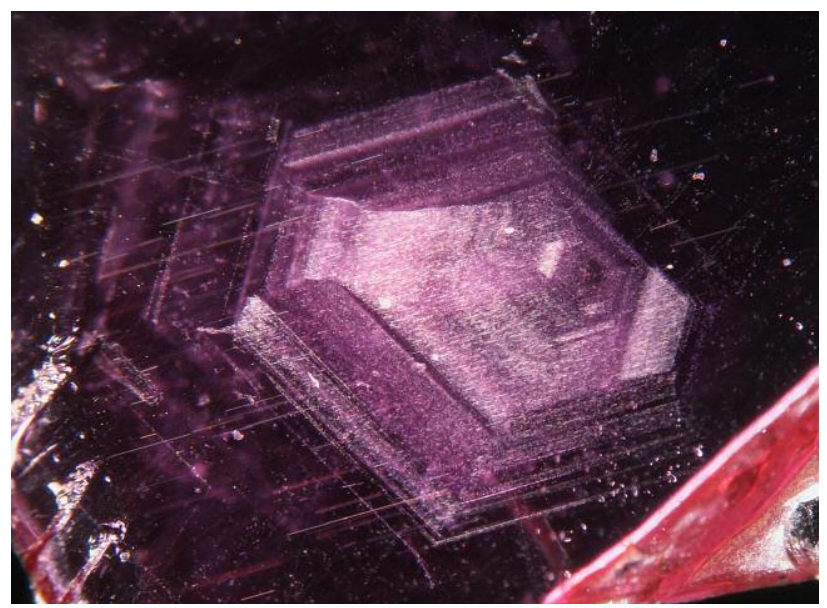


TABLE 1. Generalized trace element profiles in ppma of marble-hosted rubies.

\begin{tabular}{|c|c|c|c|c|c|}
\hline & \multicolumn{5}{|c|}{ Myanmar (Mogok) } \\
\hline & $\mathrm{Mg}$ & $\mathrm{Ti}$ & $\mathrm{V}$ & $\mathrm{Fe}$ & $\mathrm{Ga}$ \\
\hline Range & $5-75$ & $7-80$ & $48-1089$ & bdl-301 & $2-51$ \\
\hline Average & 40 & 45 & 212 & 35 & 18 \\
\hline \multirow[t]{3}{*}{ Median } & 40 & 44 & 158 & 22 & 17 \\
\hline & \multicolumn{5}{|c|}{ Myanmar (Mong Hsu) } \\
\hline & $M g$ & $\mathrm{Ti}$ & $\mathrm{V}$ & $\mathrm{Fe}$ & $\mathrm{Ga}$ \\
\hline Range & $6-68$ & 5-997 & $51-229$ & bdl-28 & $8-23$ \\
\hline Average & 23 & 247 & 123 & 2 & 15 \\
\hline \multirow[t]{3}{*}{ Median } & 19 & 176 & 112 & bdl & 16 \\
\hline & \multicolumn{5}{|c|}{ Vietnam } \\
\hline & $M g$ & $\mathrm{Ti}$ & V & $\mathrm{Fe}$ & $\mathrm{Ga}$ \\
\hline Range & $1-130$ & bdl-1214 & $2-214$ & bdl-471 & $1-122$ \\
\hline Average & 33 & 132 & 43 & 54 & 21 \\
\hline \multirow[t]{3}{*}{ Median } & 24 & 60 & 27 & 24 & 20 \\
\hline & \multicolumn{5}{|c|}{ Afghanistan } \\
\hline & $M g$ & $\mathrm{Ti}$ & $\mathrm{V}$ & $\mathrm{Fe}$ & $\mathrm{Ga}$ \\
\hline Range & $7-380$ & $9-486$ & $4-135$ & bdl-1128 & $5-35$ \\
\hline Average & 33 & 68 & 34 & 124 & 14 \\
\hline \multirow[t]{3}{*}{ Median } & 27 & 42 & 30 & 105 & 12 \\
\hline & \multicolumn{5}{|c|}{ Tajikistan } \\
\hline & $\mathrm{Mg}$ & $\mathrm{Ti}$ & $\mathrm{V}$ & $\mathrm{Fe}$ & $\mathrm{Ga}$ \\
\hline Range & $6-58$ & bdl-579 & 24-112 & bdl-155 & $14-28$ \\
\hline Average & 15 & 127 & 38 & 36 & 21 \\
\hline Median & 13 & 91 & 34 & bdl & 20 \\
\hline
\end{tabular}

${ }^{*}$ bdl = below the detection limit of the LA-ICP-MS analysis. Detection limits are provided in the Samples and Analytical Methods section, p. 581.

data are produced from LA-ICP-MS; see Groat et al., 2019, pp. 512-535 of this issue.) But as with metamorphic blue sapphires, in some cases there is simply too much overlap in the trace element data and no amount of statistical analysis or variation in plotting the data will help (figure 55). Unfortunately, this is the limitation of geographic origin determination imposed by the forces of nature and geology that created these fine stones. An "inconclusive" call is always warranted if the gemological evidence does not produce any clear indication of origin. Note that for the sake of clarity the plots shown here include only the major marble-hosted ruby deposits, while some smaller deposits (especially from East Africa) are not included. In laboratory practice, the trace element data for these deposits can be considered as possibilities if there is other corroborating evidence.
Trace Element Chemistry of High-Iron Ruby. Stones in the high-iron ruby group are much easier to separate than marble-hosted rubies by using multiple lines of evidence. Even in cases where microscopy alone cannot determine a ruby's provenance, which is fairly uncommon, the addition of trace element analysis almost always results in an accurate origin conclusion. The full range of trace element profiles for highiron rubies can be found in table 2 . Several trace element plots are shown in figure 56 , illustrating how the use of only a few trace elements can almost always separate high-iron rubies from the major mining areas. (Note that all trace element data are produced from LA-ICP-MS; see Groat et al., 2019, pp. 512-535 of this issue.) The selective plotting method used for blue sapphires and marble-hosted rubies at GIA (see Palke et al., 2019, pp. 536-579 of this issue) is sometimes 


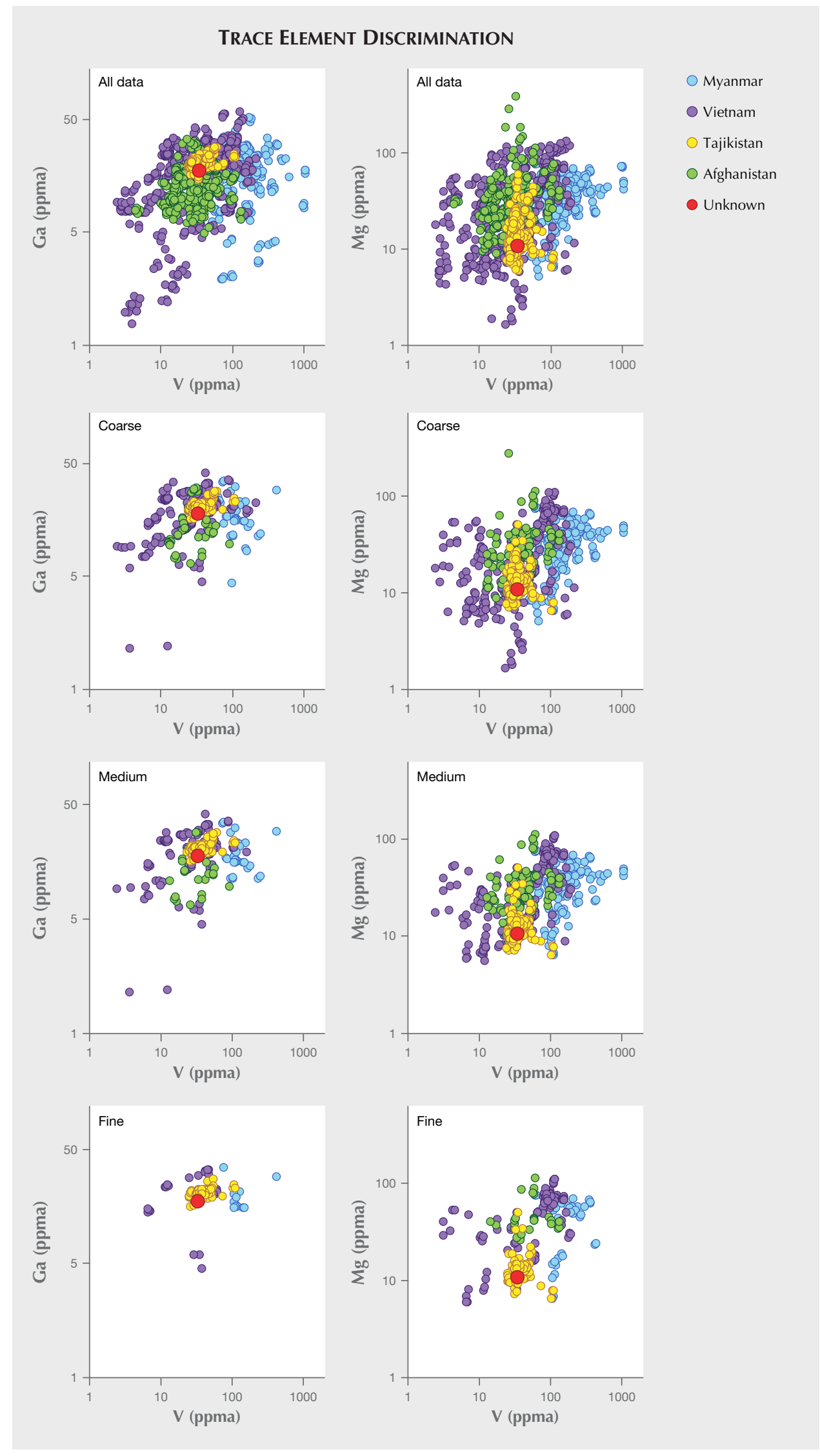

Figure 54. Trace element plots for marblehosted rubies showing data for Myanmar, Vietnam, Afghanistan, and Tajikistan, as well as an unknown ruby. The trace element profile of an unknown marble-hosted ruby (indicated by the red circle in each plot) may not provide much information when plotted against the full dataset from GIA's field gemology reference collection. In some cases, however, the "selective plotting" method used in GIA's laboratory may help to make sense of this data, providing more evidence of a stone's origin, as with this Tajik ruby. Selective plotting uses coarse, medium, and fine windows to filter out dissimilar reference data, making the plots easier to interpret. 


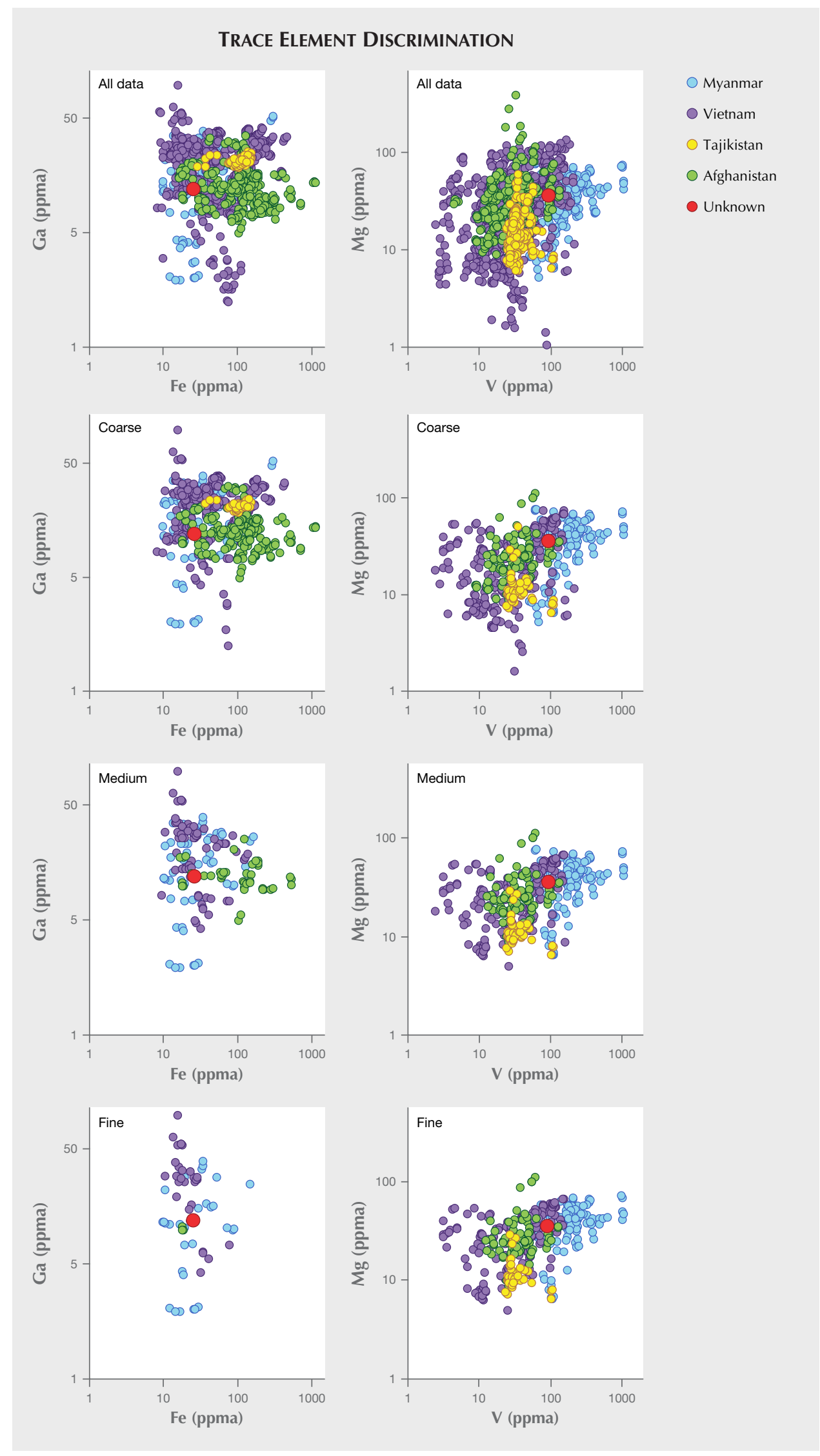

Figure 55. Trace element plots for marblehosted rubies showing data for Myanmar, Vietnam, Afghanistan, and Tajikistan, as well as an unknown stone. While the selective plotting method is useful in some cases, many marble-hosted rubies have such overlapping trace element profiles, which renders the trace element data useless in origin determination. This unknown ruby (indicated by the red circles) is a prime example. The selective plotting uses coarse, medium, and fine windows to filter out dissimilar reference data, making the plots easier to interpret. 


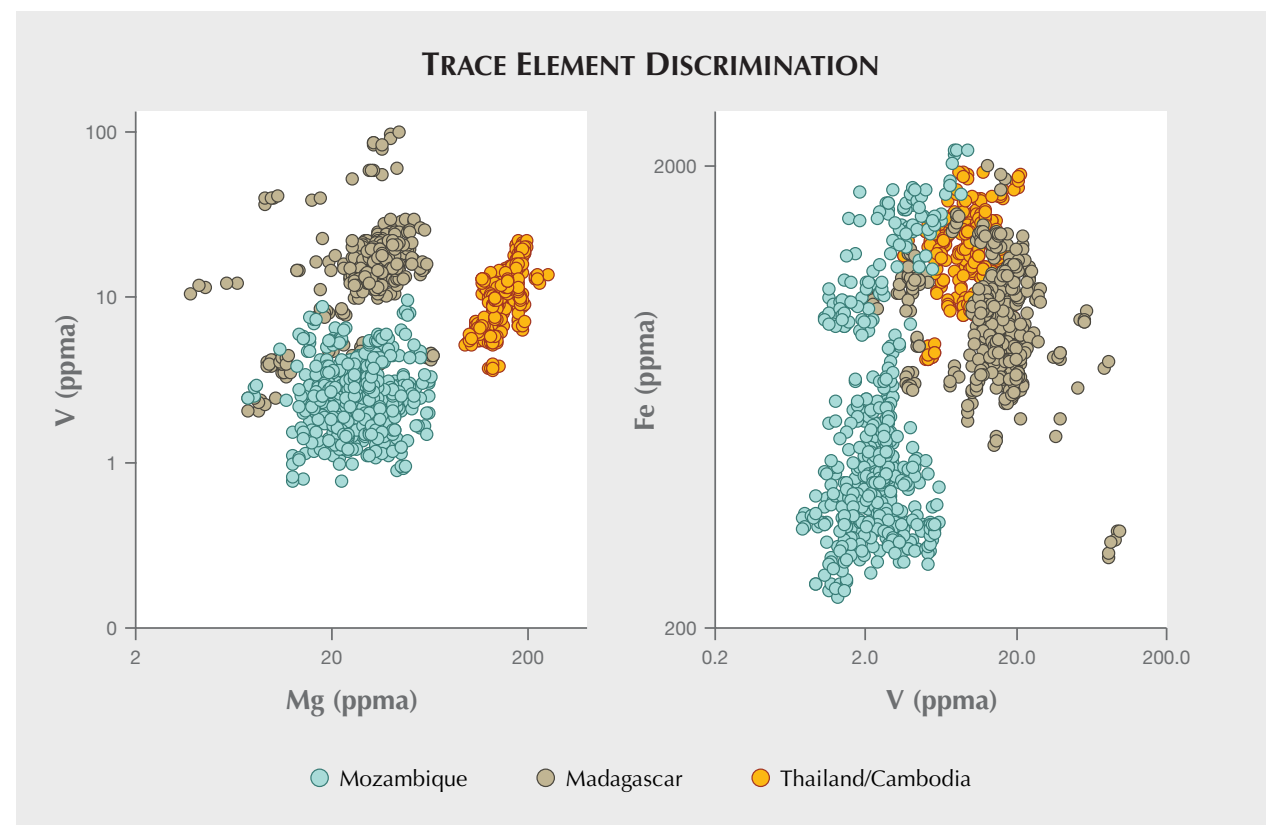

Figure 56. High-iron rubies from Mozambique, Madagascar, and Thailand/Cambodia, among others, are much easier to separate using trace element chemistry. The vast majority can be separated without needing the selective plotting method used at GIA for blue sapphires and other rubies.

used for high-iron rubies as well, but in most cases it is not necessary. Note that for the sake of clarity, these plots show only the major high-iron ruby deposits, while some smaller deposits such as those in Tanzania, Kenya, and Greenland are not included. In laboratory practice, the trace element data for these

TABLE 2. Generalized trace element profiles in ppma of high-iron rubies.

\begin{tabular}{|c|c|c|c|c|c|}
\hline \multicolumn{6}{|c|}{ Cambodia } \\
\hline & $\mathrm{Mg}$ & $\mathrm{Ti}$ & $\mathrm{V}$ & $\mathrm{Fe}$ & $\mathrm{Ga}$ \\
\hline Range & $97-258$ & $32-138$ & $5-22$ & 818-1935 & $5-11$ \\
\hline Average & 154 & 77 & 11 & 1317 & 9 \\
\hline \multirow[t]{3}{*}{ Median } & 151 & 74 & 11 & 1325 & 9 \\
\hline & \multicolumn{5}{|c|}{ Thailand } \\
\hline & $\mathrm{Mg}$ & $\mathrm{Ti}$ & V & $\mathrm{Fe}$ & $\mathrm{Ga}$ \\
\hline Range & $126-181$ & $36-89$ & $4-14$ & $756-1442$ & $5-10$ \\
\hline Average & 143 & 54 & 8 & 1089 & 8 \\
\hline \multirow[t]{3}{*}{ Median } & 138 & 51 & 7 & 1183 & 7 \\
\hline & \multicolumn{5}{|c|}{ Madagascar } \\
\hline & $\mathrm{Mg}$ & $\mathrm{Ti}$ & $\mathrm{V}$ & $\mathrm{Fe}$ & $\mathrm{Ga}$ \\
\hline Range & bdl-67 & $4-434$ & $2-100$ & 284-1994 & $5-30$ \\
\hline Average & 32 & 42 & 17 & 933 & 15 \\
\hline \multirow[t]{3}{*}{ Median } & 33 & 34 & 15 & 887 & 15 \\
\hline & \multicolumn{5}{|c|}{ Mozambique } \\
\hline & $\mathrm{Mg}$ & $\mathrm{Ti}$ & $\mathrm{V}$ & $\mathrm{Fe}$ & $\mathrm{Ga}$ \\
\hline Range & $8-65$ & bdl-59 & bdl-10 & $231-2154$ & $5-14$ \\
\hline Average & 29 & 21 & 3 & 622 & 8 \\
\hline Median & 27 & 20 & 2 & 431 & 7 \\
\hline
\end{tabular}

${ }^{*} b d l=$ below the detection limit of the LA-ICP-MS analysis. Detection limits are provided in the Samples and Analytical Methods section, p. 581. 
deposits can be considered as possibilities if there is other corroborating evidence. Additional information about these deposits can be found in Thirangoon (2009), Smith et al. (2016), and Hughes et al. (2017).

\section{CONCLUSIONS}

The twentieth and twenty-first centuries have seen dramatic changes in the world ruby market. The rapid increase in ruby sources across the world has largely benefited the gem-consuming public by making these precious stones more accessible over a wide range of price points. However, as the gem industry has come to incorporate geographic origin in determining the value of these stones (e.g., the Burmese ruby and sapphire in figure 57), this diversification of ruby sources has proven to be a great challenge for gemological laboratories. Through 10 years of efforts, GIA's field gemology and research departments have amassed world-class collections of rubies from the major world sources. The data collected on these reference stones has been crucial in allowing GIA to make origin determinations with the utmost confidence and integrity (even when the origin call is necessarily "inconclusive"). Nonetheless, the data and methods used at GIA for making ruby origin determinations, as described in this article, demonstrate the oftentimes precarious nature of origin determination in gemological laboratories.
Many stones present characteristic inclusion scenes that lead to a straightforward origin decision. This is often the case with rubies from Thailand, Mozambique, Madagascar, and rubies from some of the marble-hosted deposits, especially those from Myanmar (figure 58). Rubies from the other marblehosted deposits such as Vietnam, Afghanistan, and Tajikistan are generally more challenging. Trace element chemistry can be useful, especially for so-called high-iron rubies. Unfortunately, and especially for marble-hosted rubies, trace element chemistry can often be ambiguous.

The use of the "selective plotting" method described herein may help in making sense of this trace element data, but it is hardly a cure-all. In cases where the inclusion scenes and trace element evidence are ambiguous, the only possible determination is an "inconclusive" origin. Future research and field gemology efforts will focus on advancing our understanding of ruby origin determination and refining the methods used in the laboratory at GIA. However, it is almost certain that there will always be rubies with a lack of characteristic origin data to support an origin conclusion. While further work may help us reduce the number of "inconclusive" calls, the overlap in gemological properties for many of our reference stones makes it unlikely that this number will ever reach zero.

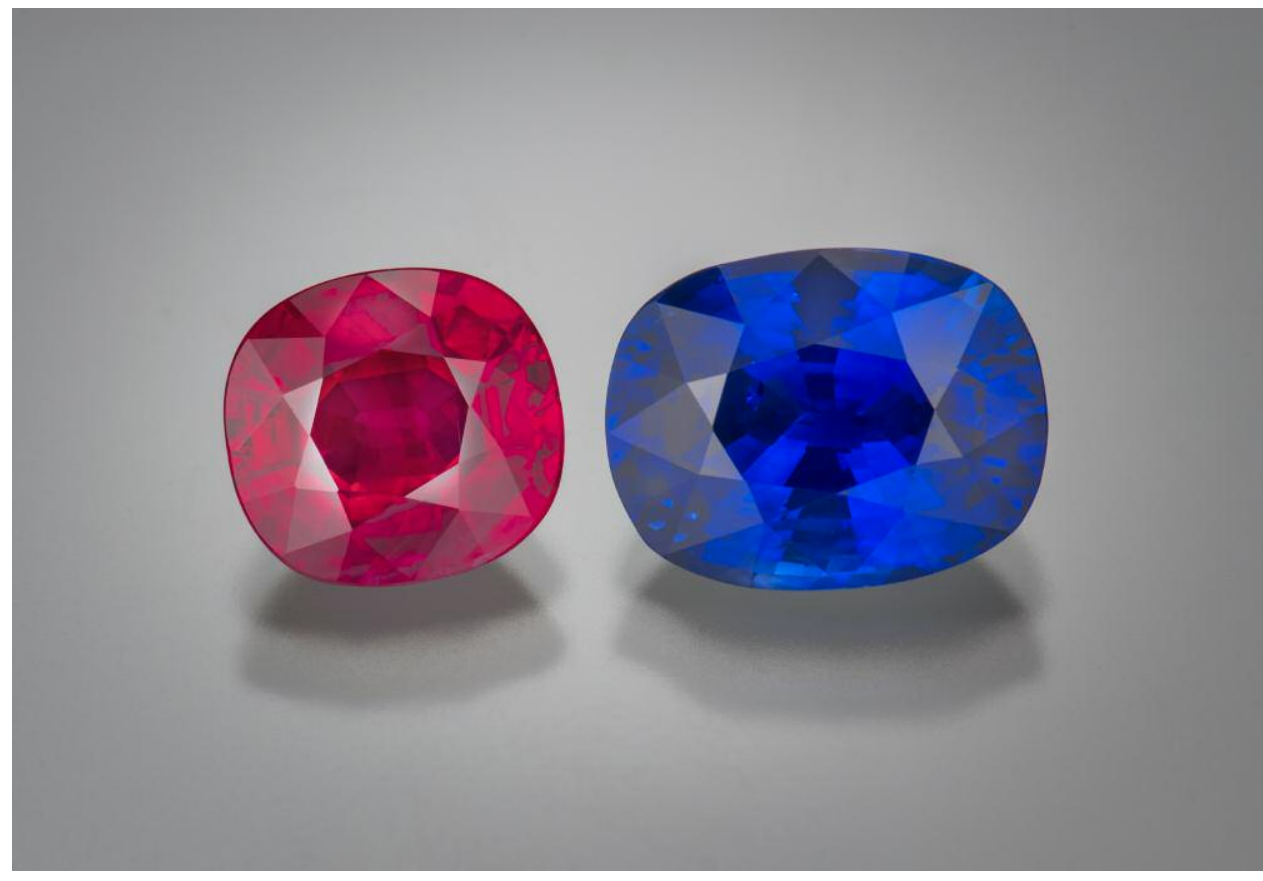

Figure 57. A 2.58 ct cushion-cut ruby and a 4.47 ct cushion-cut blue sapphire, both of Burmese origin. Photo by Robert Weldon/GIA; courtesy of Bear Essentials. 


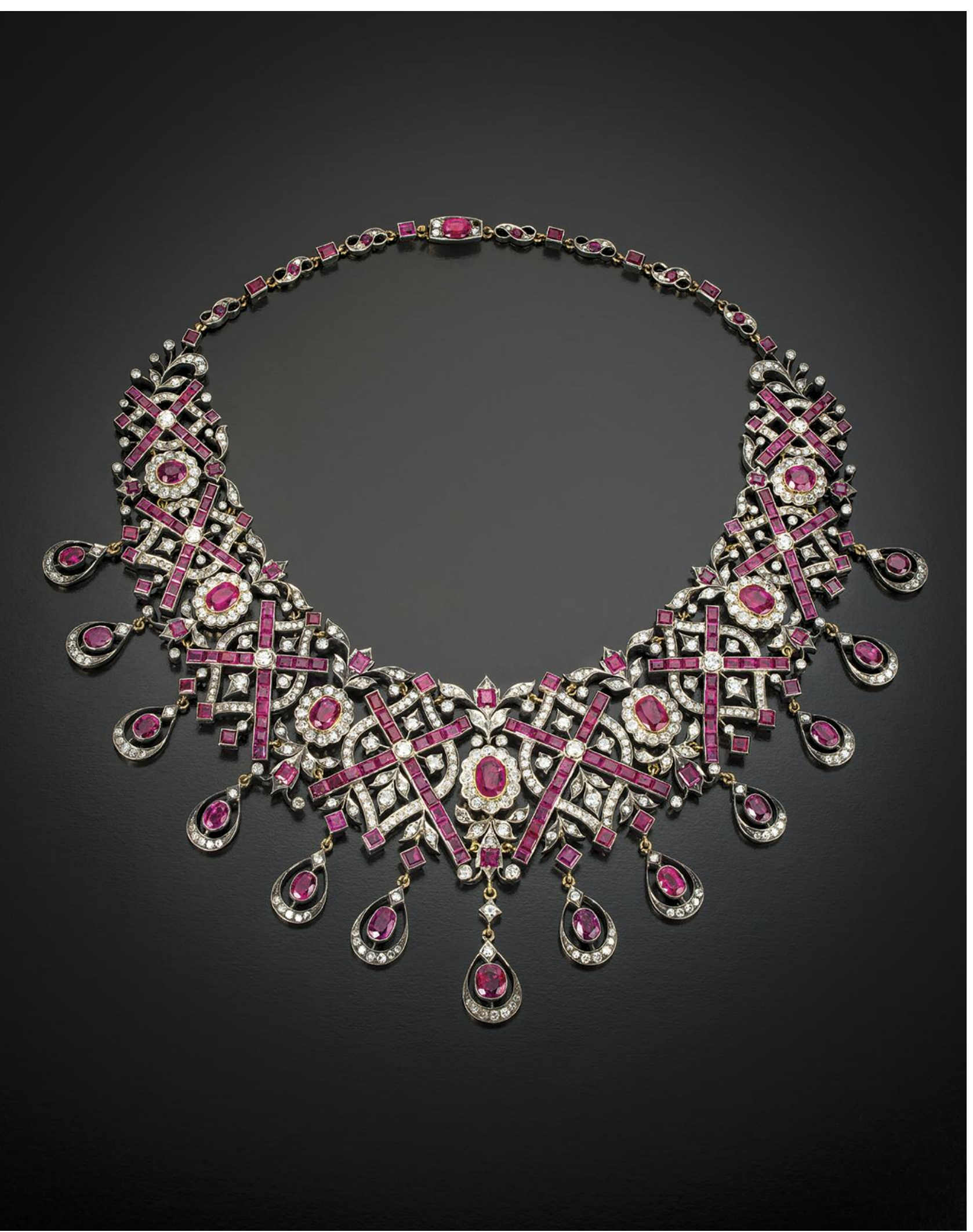

Figure 58. This necklace contains approximately 50 carats of rubies, including 28 oval and numerous square and rectangular rubies. All the rubies are of Burmese origin with no evidence of heat. Photo by Robert Weldon/GIA; courtesy of Ronny Levy, Period Jewels Inc. 


\section{CASe Study 1: Burmese Ruby}

In the first ruby case study, we consider the 2.21 ct ruby shown in figure CS 1-1. LA-ICP-MS analysis measures an Fe concentration of 28 ppma, placing this stone in the marble-hosted ruby group and narrowing down the possible origins to Myanmar, Vietnam, Afghanistan, and Tajikistan. The next step is to make careful observations of its inclusion characteristics. Viewed through the microscope, this stone exhibits nested, straw-like silk that is strongly reminiscent of classic rubies from Mogok, Myanmar (figure CS 1-2). Also seen are large crystalline inclusions of apatite and other minerals, which support a Burmese origin (figure CS 1-3). While the inclusion evidence points strongly toward a Burmese origin, trace element chemistry should be considered carefully as well. Without using the selective plotting method described in this article and in Palke et al. (2019, pp. 536-579 of this issue), this unknown stone plots in a field of overlapping Myanmar and Vietnam reference data (figure CS 1-4). However, filtering the data using the selective plotting method narrows down this field and shows a clear match with other Burmese rubies in the GIA colored stone reference collection. Taking all the data together, we can confidently assign a Burmese origin to this stone.

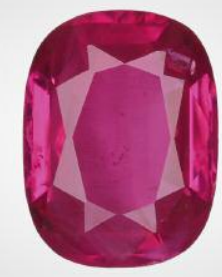

Figure CS 1-1. A $2.21 \mathrm{ct}$ mixed-cut ruby considered for geographic origin determination. Photo by Diego Sanchez.

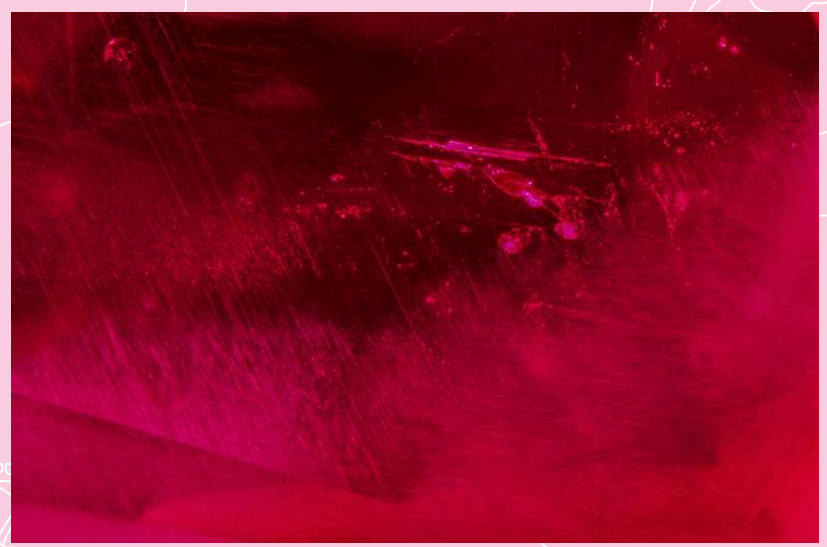

Figure CS 1-2. Nested straw-like silk and crystalline inclusions strongly suggest a Burmese origin. Photomicrograph by Aaron Palke; field of view $4.48 \mathrm{~mm}$.

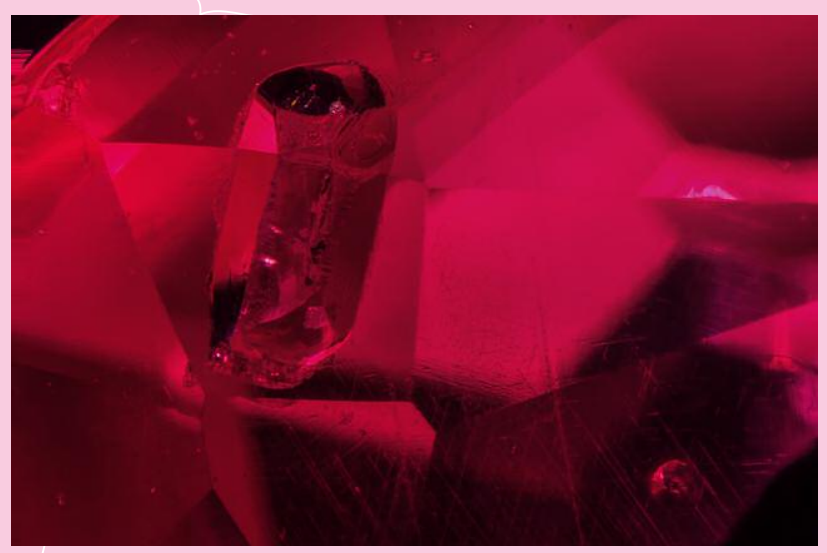

Figure CS 1-3. A crystalline inclusion of apatite is consistent with Burmese origin. Photomicrograph by Aaron Palke; field of view $2.84 \mathrm{~mm}$. 


\section{TRACE EleMENT DisCRIMINATION}
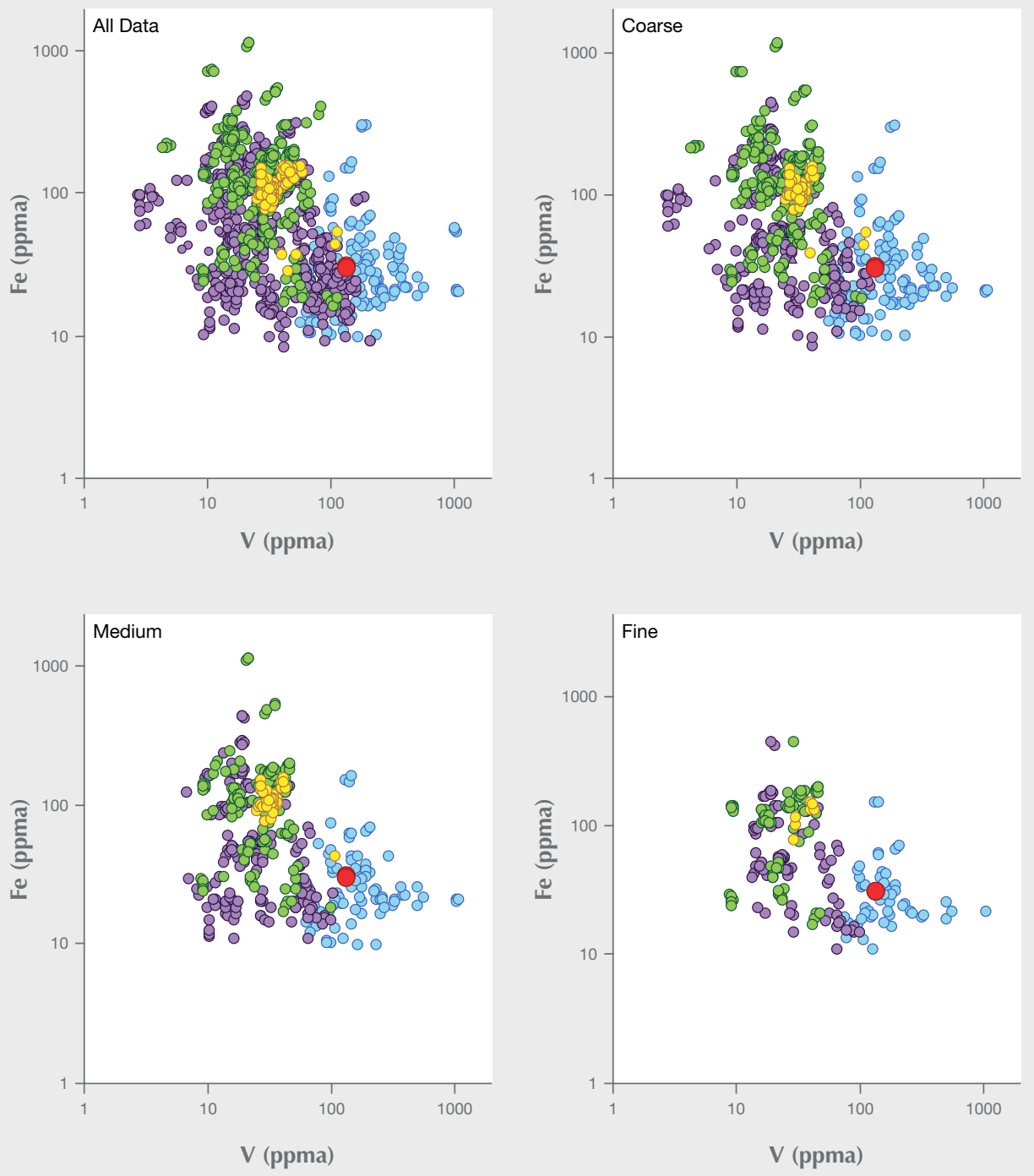

Myanmar Vietnam Tajikistan O Afghanistan Onknown

Figure CS 1-4. Trace element analysis supports a Burmese origin for this ruby (indicated by the red circle). 


\section{CASE StUdy 2: TAJIK RUBY}

In this case study we investigate the $0.16 \mathrm{ct}$ step-cut ruby shown in figure CS 2-1. Precise measurement of the trace element profile indicates an Fe concentration of 41 ppma, placing it in the marble-hosted ruby group. This essentially simplifies the origin determination problem to a choice between Myanmar, Vietnam, Afghanistan, and Tajikistan. Observation of the inclusion scenes in marble-hosted rubies can help narrow down this field even further and can often lead to a conclusive origin determination. Among the inclusions observed in this stone are crystals with rosette-like haloes (figure CS 2-2), polyphase aggregated solid inclusions, and clusters of slender tourmaline crystals (figure CS 2-3). All of these features are indicative of a Tajik origin. Additional corroborating evidence can be sought in the stone's trace element fingerprint. Figure CS 2-4 shows representative trace element plots of the unknown ruby against GIA's marble-hosted ruby database. The use of the selective plotting method allows clearer interpretation of the trace element data and shows this stone is more consistent with the Tajik ruby reference data than any other source. Taken together, the data collected for this stone allows a Tajik origin determination.

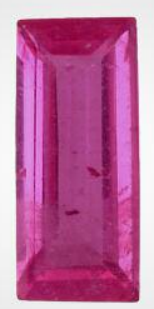

Figure CS 2-1. The 0.16 ct ruby under consideration in this geographic origin determination case study. Photo by Diego Sanchez.

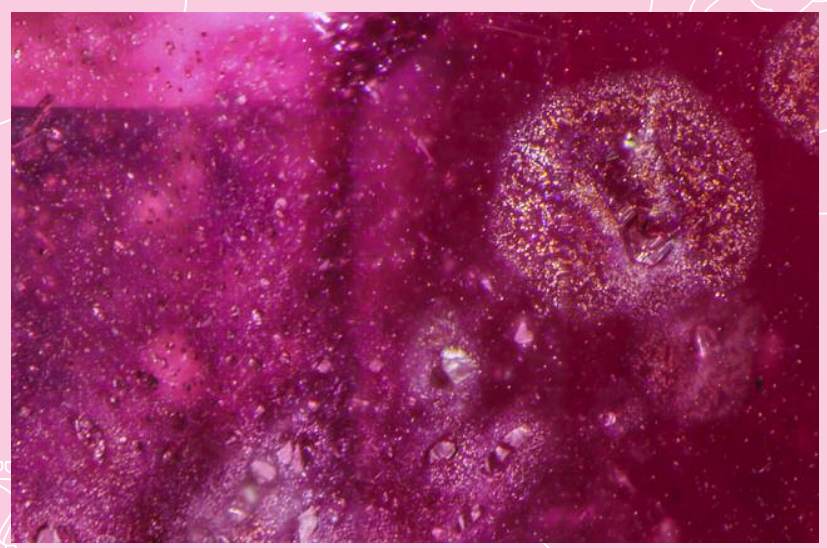

Figure CS 2-2. The rosette-like fringe around this inclusion is suggestive of a Tajik origin. Photomicrograph by Nathan D. Renfro; field of view $1.10 \mathrm{~mm}$.

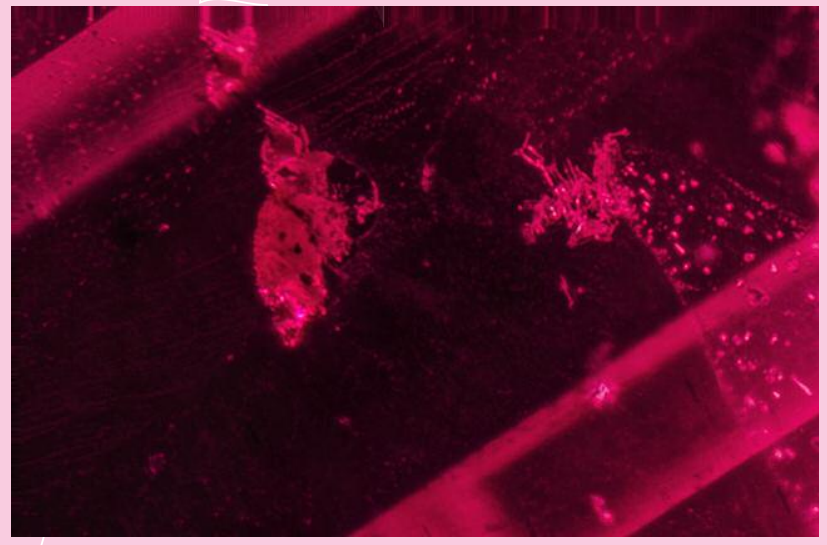

Figure CS 2-3. Clusters of slender tourmaline crystals (upper right) and polyphase, aggregate solid inclusions (left) corroborate a Tajik origin determination. Photomicrograph by Aaron C. Palke; field of view $1.77 \mathrm{~mm}$. 


\section{TRACE ELEMENT DisCriminATION}
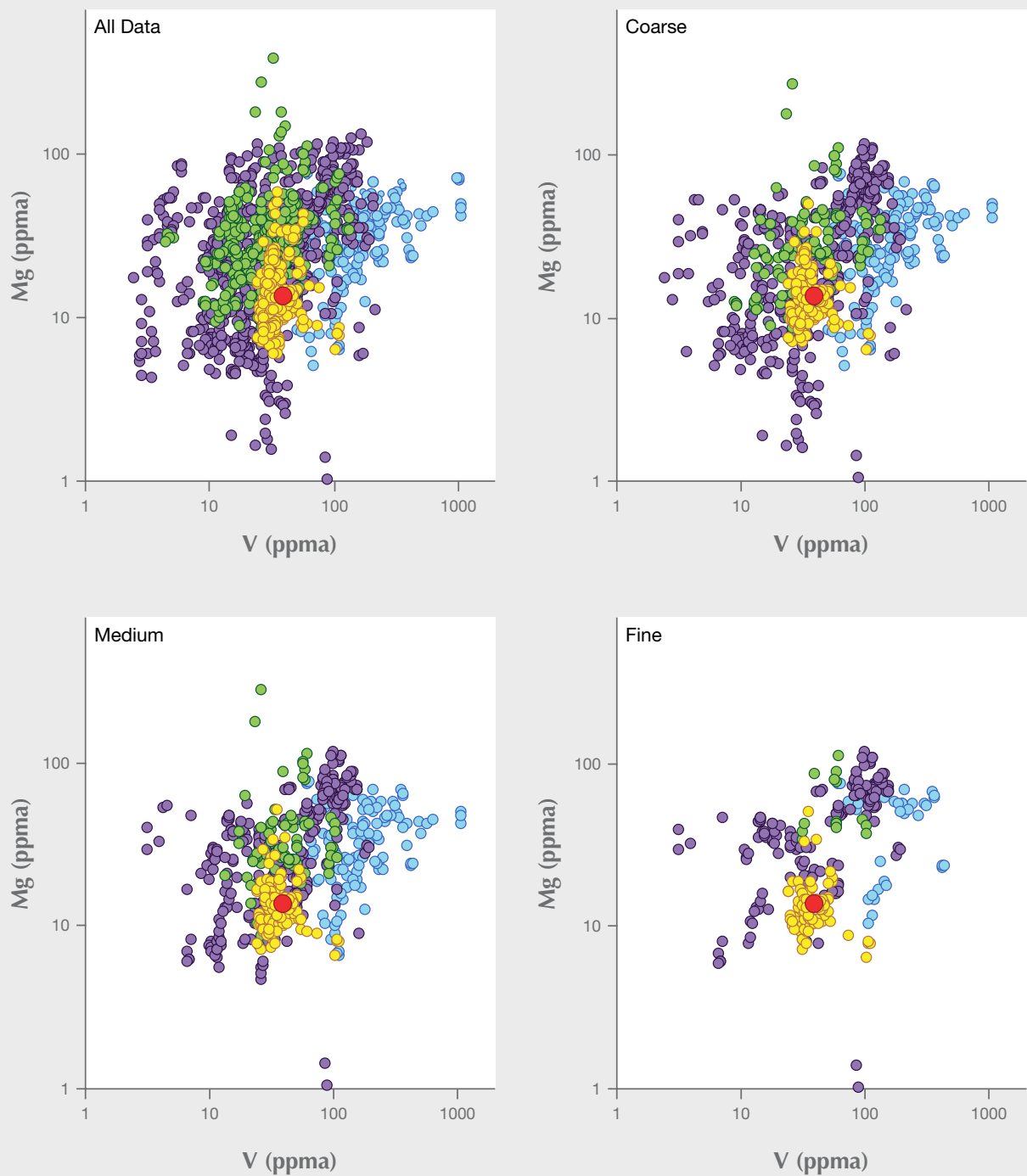

Myanmar $\bigcirc$ Vietnam Tajikistan $\bigcirc$ Afghanistan Unknown

Figure CS 2-4. Trace element analysis of this unknown ruby (indicated by the red circle) favors a Tajik origin. 


\section{CASE Study 3: MAdAGASCAR Ruby}

For the third case study, we will consider the 0.39 ct ruby shown in figure CS 3-1. Its Fe concentration was measured at 2720 ppma, so the unknown stone belongs to the so-called high-iron ruby group. The most likely geographic origins, therefore, include Mozambique, Madagascar, and Thailand/Cambodia. Microscopic observation provides the gemologist with an inclusion scene such as the one seen in figure CS 3-2. With an intense fiber-optic light at just the right angle, the reflective rutile silk in the stone lights up and provides the first clue to origin. Similar inclusion scenes can be seen in both Mozambique and Madagascar rubies, but rutile silk like this is never found in Thai/Cambodian rubies. However, the observation of zircon clusters provides strong evidence of a Madagascar origin for this stone (figure CS 3-3). Advanced testing involving precise measurement of the trace element signature using LA-ICP-MS is required as additional evidence to support an origin determination. The representative trace element plot shown in figure CS 3-4 confirms a Madagascar origin.

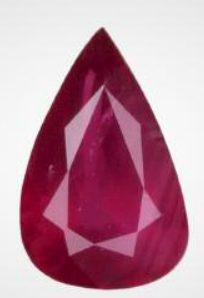

Figure CS 3-1. This case study considers a 0.39 ct ruby for geographic origin determination. Photo by Diego Sanchez.

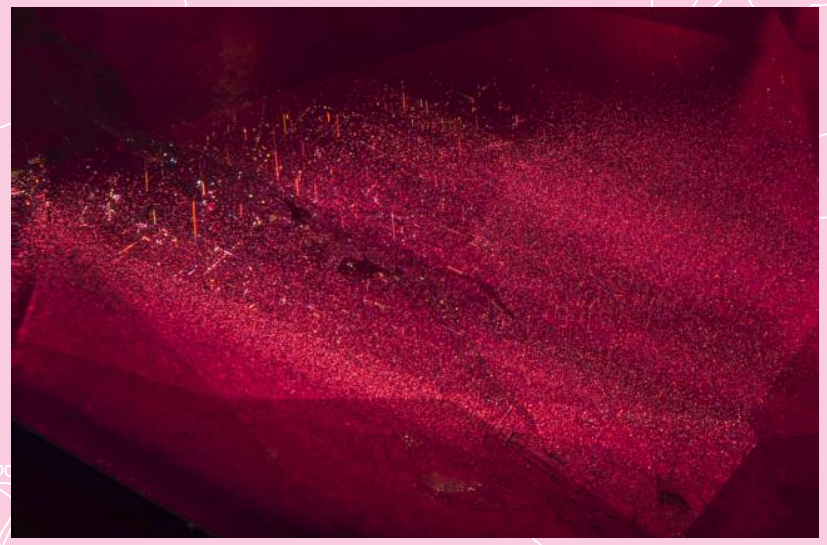

Figure CS 3-2. Particulate clouds and short, iridescent silk are not characteristic of any unique origin. Photomicrograph by Aaron C. Palke; field of view $3.97 \mathrm{~mm}$.

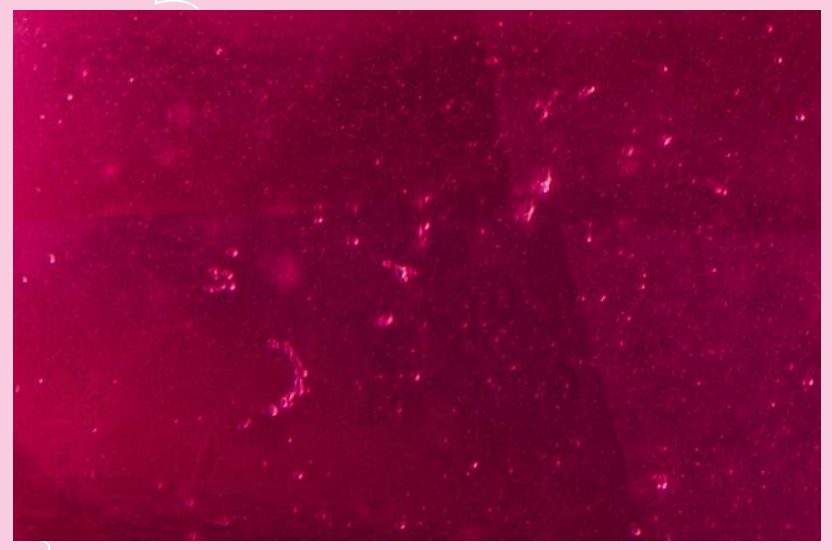

Figure CS 3-3. The zircon clusters in this ruby strongly indicate a Madagascar origin. Photomicrograph by Nathan D. Renfro; field of view $1.02 \mathrm{~mm}$. 


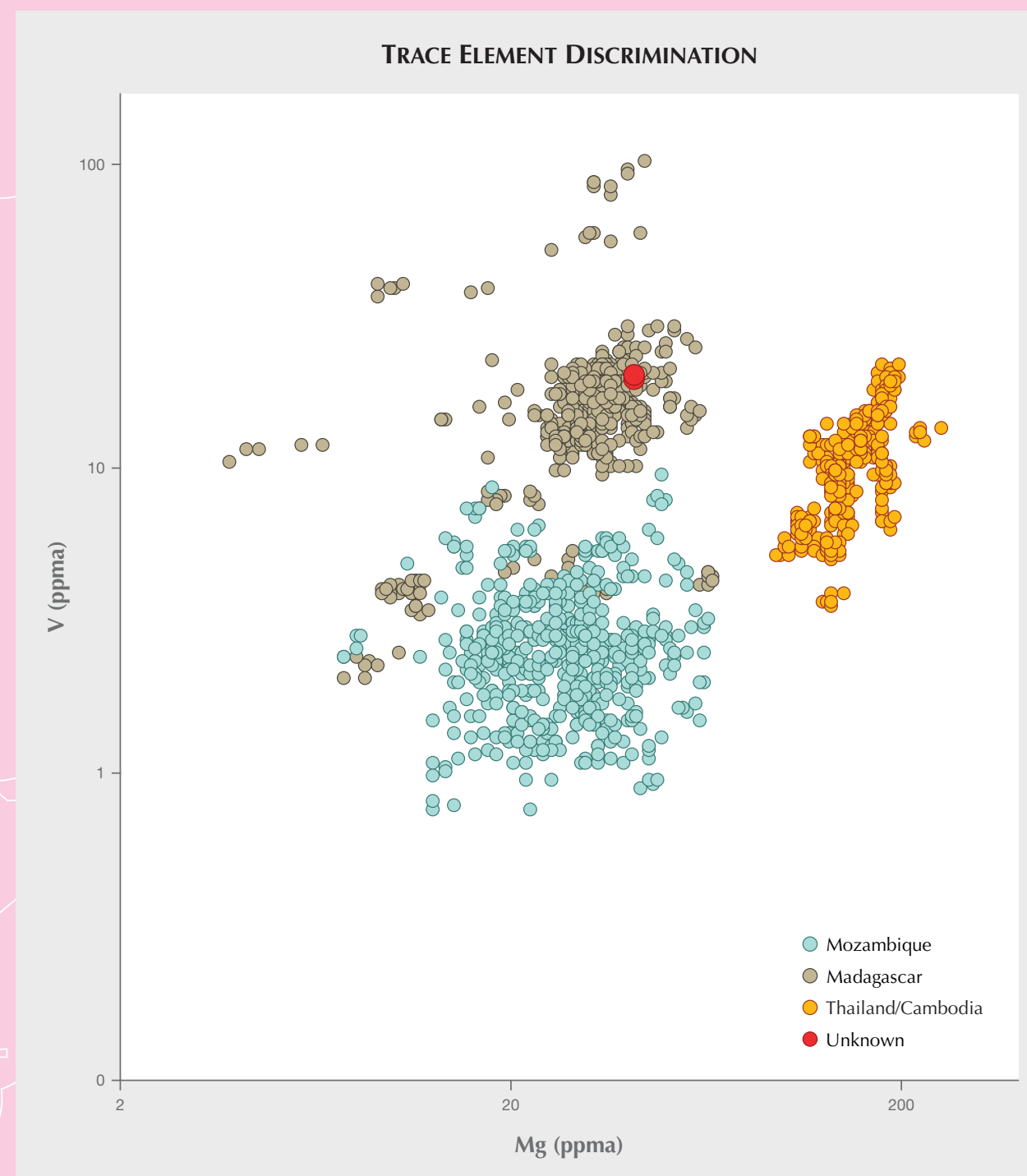

Figure CS 3-4. Trace element analysis of this unknown ruby (indicated by the red circle) indicates a Madagascar origin. 


\section{CASE Study 4: InCONClusive Ruby}

The final case study involves a 0.22 ct ruby (figure CS 4-1). Trace element analysis measured an Fe concentration of 449 ppma, placing it in the high-iron ruby group. The main geographic locales to be considered, then, are Mozambique, Madagascar, and Thailand/Cambodia. The next step in uncovering this unknown ruby's origin is careful observation of inclusions in the gemological microscope. While this stone is not especially clean, unfortunately it contains no particularly diagnostic or indicative inclusions. The main inclusion feature is a fingerprint-like veil of fluid inclusions (figure CS 4-2). Regardless, the geographic origin of many high-iron rubies can be confidently determined by trace element analysis, even when there are no useful inclusions to be found. However, this stone remains a mystery even after precisely measuring its trace element fingerprint using LA-ICP-MS (figure CS 4-3). The chemical data plot outside the defined fields for any reference rubies from known deposits. While the selective plotting method does seem to display some affinity for Madagascar as a possible source, the unknown stone is still outside the range from our reference collection. Given that there is also no inclusion evidence to corroborate a Madagascar origin, the best option is an "inconclusive" origin determination.

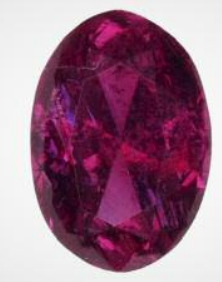

Figure CS 4-1. A 0.22 ct ruby is the focus of geographic origin determination in this case study. Photo by Diego Sanchez.

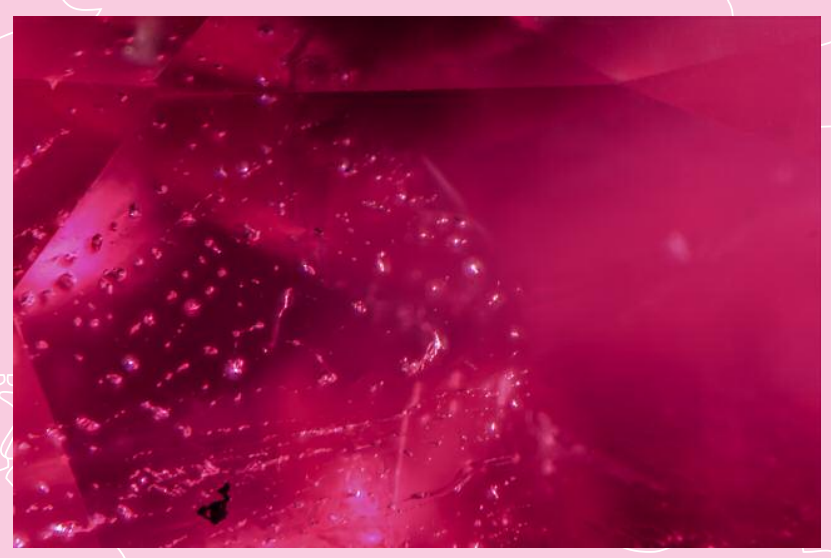

Figure CS 4-2. No diagnostic inclusions are observed. The only inclusion features identified are fingerprintlike fields of fluid inclusions. Photomicrograph by Nathan D. Renfro; field of view $2.05 \mathrm{~mm}$. 


\section{TRACE ELEMENT DisCRIMINATION}
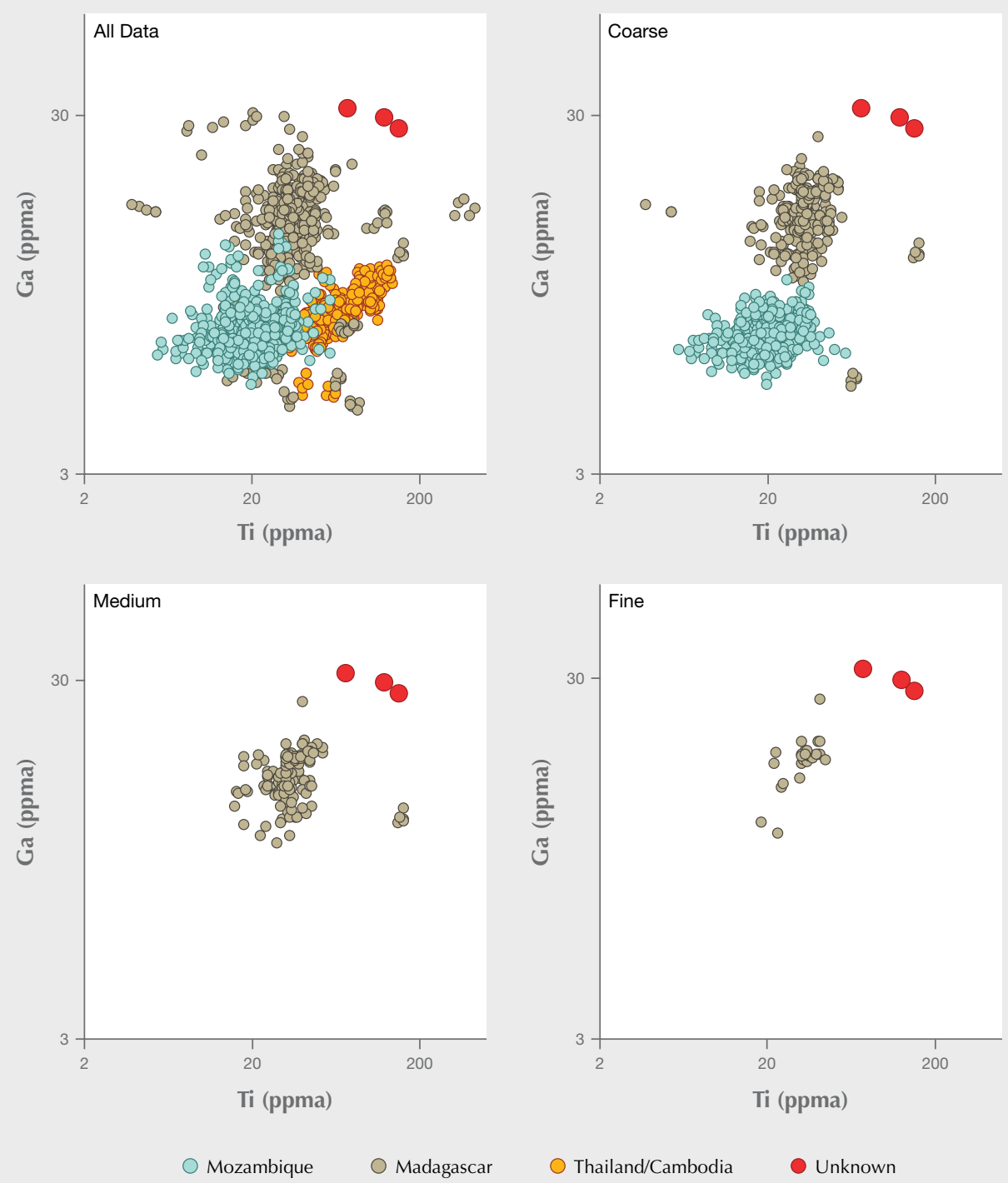

Figure CS 4-3. Trace element analysis of this unknown ruby (indicated by the red circle) fails to produce a unique match with any of the reference data for stones of known provenance. 
ABOUT THE AUTHORS

Dr. Palke is a senior research scientist, Mr. Renfro is manager of colored stone identification, Mr. Sun is a research associate, and Mr. McClure is global director of colored stone services, at GIA in Carlsbad, California. Ms. Saeseaw is senior manager of identification at GIA in Bangkok.

\section{ACKNOWLEDGMENTS}

The authors wish to express their gratitude for colleagues at GIA and elsewhere who have helped advance the knowledge of origin determination for rubies and who have otherwise helped put this article together, including Dino DeGhionno, Claire Malaquais, Philip Owens, Philip York, Nicole Ahline, John Koivula, Jennifer Stone-Sundberg, Barbara Dutrow, and John Valley, among others. Terri Ottaway and McKenzie Santimer from the GIA Museum are also to be thanked for their support in the research efforts in the lab at GIA. We also thank Lin Sutherland, Hanco Zwaan, and Ahmadjan Abduriyim for their thorough reviews of this manuscript and helpful comments and criticism.

\section{REFERENCES}

Bowersox G.W., Foord E.E., Laurs B.M., Shigley J.E., Smith C.P. (2000) Ruby and sapphire from Jegdalek, Afghanistan. $G e$ ) Vol. 36, No. 2, pp. 110-126, http://dx.doi.org/10.5741/ GEMS.36.2.110

Brown G. (1992) Vietnamese ruby: A discriminatory problem for gemmologists. Australian Gemmologist, Vol. 18, No. 2, pp. 43 46.

Chapin M., Pardieu V., Lucas A. (2015) Mozambique: A ruby discovery for the 21 st century. Ge G, Vol. 51, No. 1, pp. 44-54, http://dx.doi.org/10.5741/GEMS.51.1.44

Emmett J.L., Scarratt K., McClure S.F., Moses T., Douthit T.R., Hughes R., Novak S., Shigley J.E., Wang W., Bordelon O., Kane R.E. (2003) Beryllium diffusion of ruby and sapphire. $G \uplus G$, Vol. 39, No. 2, pp. 84-135, http://dx.doi.org/10.5741/ GEMS.39.2.84

Fanka A., Sutthirat C. (2018) Petrochemistry, mineral chemistry, and pressure-temperature model of corundum-bearing amphibolite from Montepuez, Mozambique. Arabian Journal for Science and Engineering, Vol. 43, pp. 3751-3767.

Garnier V., Giuliani G., Ohnenstetter D., Fallick A.E., Dubessy J., Banks D., Vinh H.Q., Lhomme T., Maluski H., Pecher A., Bakhsh K.A., Long P.V., Trinh P.T., Schwarz D. (2008) Marblehosted ruby deposits from Central and Southeast Asia: Towards a new genetic model. Ore Geology Reviews, Vol. 34, No. 1-2, pp. 169-191, http://dx.doi.org/10.1016/j.oregeorev.2008.03.003

Giuliani G., Groat L.A. (2019) Geology of corundum and emerald gem deposits: A review. Gせ G, Vol. 55, No. 4, pp. 464-489, http://dx.doi.org/10.5741/GEMS.55.4.464

Groat L.A., Giuliani G., Stone-Sundberg J., Renfro N.D., Sun Z. (2019) A review of analytical methods used in geographic origin determination of gemstones. Ge G, Vol. 55, No. 4, pp. 512-535, http://dx.doi.org/10.5741/GEMS.55.4.512

Gübelin E.J., Koivula J.I. (2008) Photoatlas of Inclusions in Gemstones, Volume 3. Opinio Publishers, Basel, Switzerland, 672 pp.

Hughes R.W. (1994) The rubies and spinels of Afghanistan. Journal of Gemmology, Vol. 24, No. 4, pp. 256-267.

Hughes R.W., Manorotkul W., Hughes E.B. (2015) Let it bleed: New rubies from Madagascar. http://www.lotusgemology.com/ index.php/library/articles/322-blood-red-rubies-from-madagascarlotus-gemology.

Hughes R.W., Manorotkul W., Hughes B.E. (2017) Ruby «) Sapphire: A Gemologist's Guide. RW Publishing/Lotus Publishing, Bangkok, $816 \mathrm{pp}$.

Kane R.E., McClure S.F., Kammerling R.C., Khoa N.D., Mora C., Repetto S., Khai N.D., Koivula J.I. (1991) Rubies and fancy sapphires from Vietnam. $G \uplus G$, Vol. 27, No. 3, pp. 136-155, http://dx.doi.org/10.5741/GEMS.27.3.136

Khoi N.N., Sutthirat C., Tuan D.A., Nam V.N., Minh N.T., Nhung N.J. (2011) Ruby and sapphire from the Tan HuongTruc Lau area, Yen Bai Province, northern Vietnam. $G \uplus G$,
Vol. 47, No. 3, pp. 182-196, http://dx.doi.org/10.5741/GEMS. 47.3.182

Long P.V., Vinh H.Q., Garnier V., Giuliani G., Ohnenstetter D. (2004) Marble-hosted ruby from Vietnam. Canadian Gemmologist, Vol. 25, No. 3, pp. 83-95.

Long P.V., Vinh H.Q., Garnier V., Giuliani G., Ohnenstetter D., Lhomme T., Schwarz D., Fallick A., Dubessy J., Trinh P.T. (2004) Gem corundum deposits in Vietnam. Journal of Gemmology, Vol. 29, No. 3, pp. 129-147.

Long P.V., Vinh H.Q., Nghia N.X. (2004) Inclusions in Vietnamese Quy Chau ruby and their origin. Australian Gemmologist, Vol. 22, pp. 67-71.

Mercier A., Rakotondrazafy M., Ravolomiandrinarivo B. (1999) Ruby mineralization in southwest Madagascar. Gondwana Research, Vol. 2, No. 3, pp. 433-438, http://dx.doi.org/10.1016/ S1342-937X(05)70281-1

Palke A.C., Wong J., Verdel C., Avila J.N. (2018) A common origin for Thai/Cambodian rubies and blue and violet sapphires from Yogo Gulch, Montana, U.S.A.? American Mineralogist, Vol. 103, No. 3, pp. 469-479, http://dx.doi.org/10.2138/am-20186164

Palke A.C., Saeseaw S., Renfro N.D., Sun Z., McClure S.F. (2019) Geographic origin determination of blue sapphire. Ge)G, Vol. 55, No. 4, pp. 536-579, http://dx.doi.org/10.5741/GEMS. 55.4 .536

Pardieu V., Rakotosaona N., Noverraz M., Bryl L.P. (2012) Ruby and sapphire rush near Didy, Madagascar. GIA Research News, https://www.gia.edu/ongoing-research/ruby-and-sapphire-rushnear-didy-madagascar

Peretti A., Schmetzer K., Bernhardt H.J., Mouawad F. (1995) Rubies from Mong Hsu. GÆG, Vol. 31, No. 1, pp. 2-26, http://dx.doi.org/10.5741/GEMS.31.1.2

Sangsawong S., Vertriest W., Saeseaw S., Pardieu V. (2017) A study of rubies from Cambodia and Thailand. GIA Research News, https://www.gia.edu/gia-news-research/study-rubies-cambodia-thailand

Schwarz D., Schmetzer K. (2001) Rubies from the Vatomandry area, eastern Madagascar. Journal of Gemmology, Vol. 27, No. 7, pp. 409-416.

Smith C.P. (1998) Rubies and pink sapphires from the Pamir Range in Tajikistan, former USSR. Journal of Gemmology, Vol. 26, No. 2, pp. 103-109.

Smith C.P., Fagan A.J., Bryan C. (2016) Ruby and pink sapphire from Aappaluttoq, Greenland. Journal of Gemmology, Vol. 35, No. 4, pp. 294-306.

Sorokina E.S., Litvinenko A.K., Hofmeister W., Häger T., Jacob D.E., Nasriddinov Z.Z. (2015) Rubies and sapphires from Snezhnoe, Tajikistan. GÆG, Vol. 51, No. 2, pp. 160-175, http://dx.doi.org/10.5741/GEMS.51.2.160

Stone-Sundberg J., Thomas T., Sun Z., Guan Y., Cole Z., Equall R., 
Emmett J.L. (2017) Accurate reporting of key trace elements in ruby and sapphire using matrix-matched standards. $G \uplus G$, Vol. 53, No. 4, pp. 438-451, http://dx.doi.org/10.5741/GEMS. 53.4 .438

Sutthirat C., Hauzenberger C., Chualaowanich T., Assawincharoenkij T. (2018) Mantle and deep crustal xenoliths in basalts from the Bo Rai ruby deposit, eastern Thailand: Original source of basaltic ruby. Journal of Asian Earth Sciences, Vol. 164, pp. 366-379, http://dx.doi.org/10.1016/j.jseaes.2018.07.006

Themelis T. (2008) Gems \&) Mines of Mogok. A\&T Publishers, USA, $352 \mathrm{pp}$.

Thirangoon K. (2009) Ruby and pink sapphire from Aappaluttoq,
Greenland. GIA Research News, https://www.gia.edu/gianews-research-nr32309

Vertriest W., Saeseaw S. (2019) A decade of ruby from Mozambique: A review. $G \uplus G$, Vol. 55, No. 2, pp. 162-183, http://dx.doi.org/10.5741/GEMS.55.2.162

Vertriest W., Palke A.C., Renfro N.D. (2019) Field gemology: Building a research collection and understanding the development of gem deposits. $G \uplus G$, Vol. 55, No. 4, pp. 490-511, http://dx.doi.org/10.5741/GEMS.55.4.490

Wang W. Hall M., Shen A.H., Breeding C.M. (2006) Developing corundum standards for LA-ICP-MS trace-element analysis. Ge G, Vol. 42, No. 3, pp. 105-106.

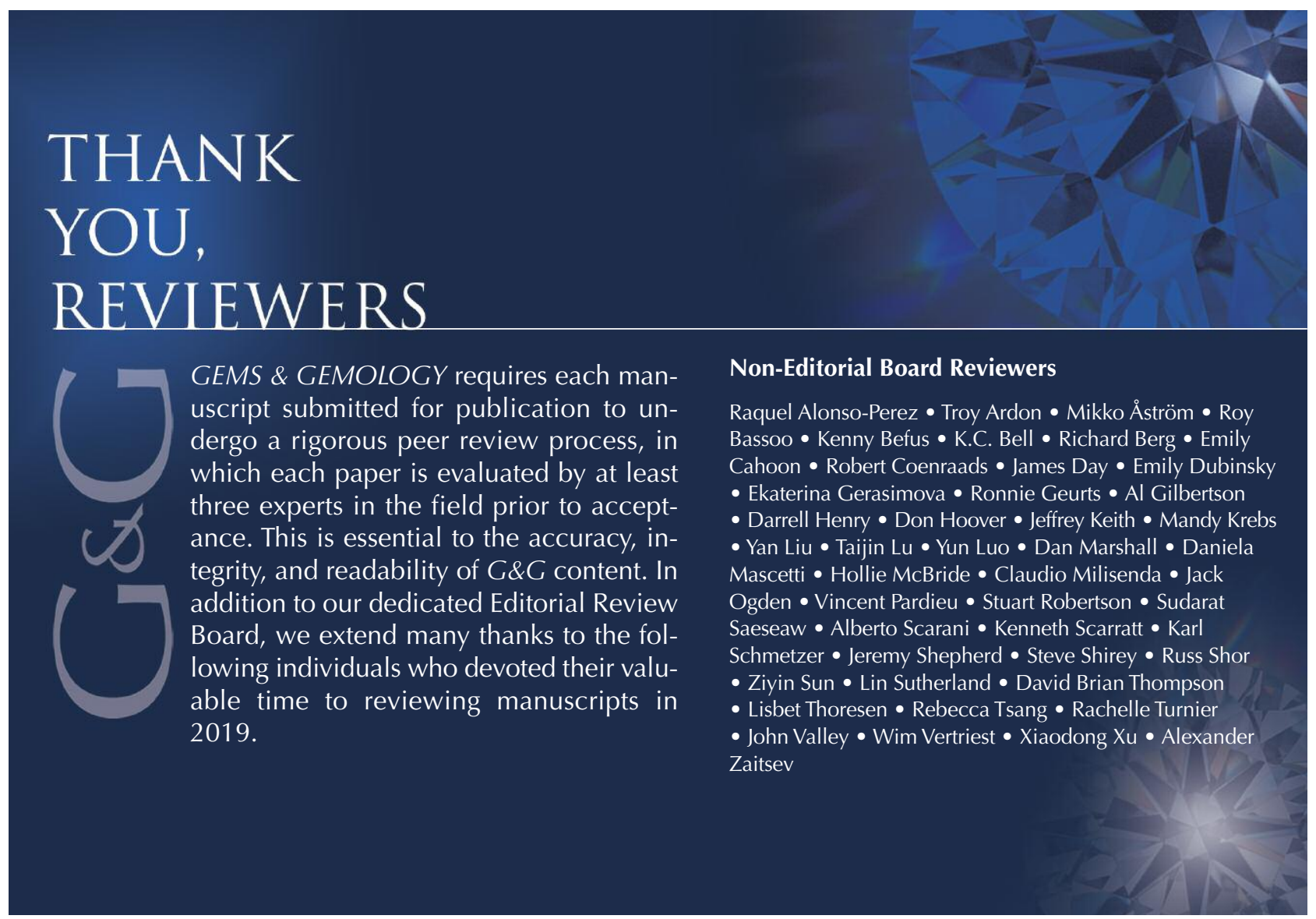

